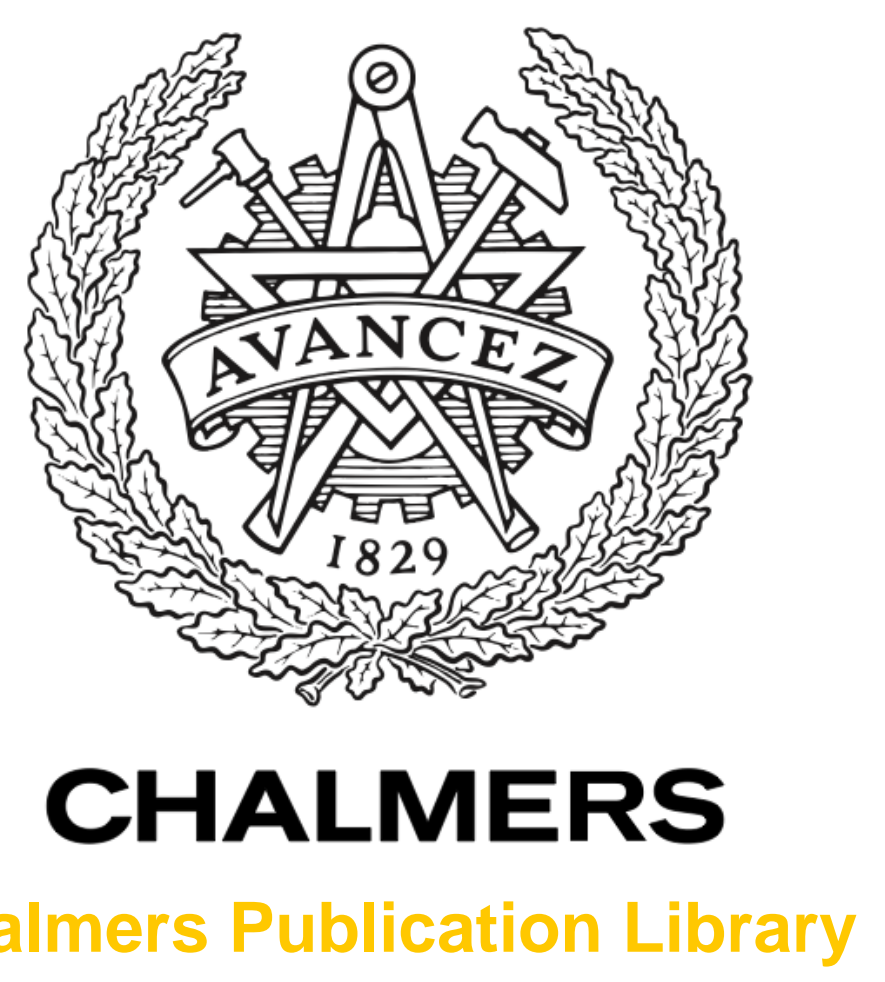

Chalmers Publication Library

\title{
A scale model study of parallel urban canyons
}

This document has been downloaded from Chalmers Publication Library (CPL). It is the author's version of a work that was accepted for publication in:

Acustica Acta-Acustica (ISSN: 1610-1928)

Citation for the published paper:

Hornikx, M. ; Forssén, J. (2008) "A scale model study of parallel urban canyons". Acustica Acta-Acustica, vol. 94(2), pp. 265-281.

http://dx.doi.org/10.3813/AAA.918030

Downloaded from: http://publications.lib.chalmers.se/publication/69867

Notice: Changes introduced as a result of publishing processes such as copy-editing and formatting may not be reflected in this document. For a definitive version of this work, please refer to the published source. Please note that access to the published version might require a subscription.

Chalmers Publication Library (CPL) offers the possibility of retrieving research publications produced at Chalmers University of Technology. It covers all types of publications: articles, dissertations, licentiate theses, masters theses, conference papers, reports etc. Since 2006 it is the official tool for Chalmers official publication statistics. To ensure that Chalmers research results are disseminated as widely as possible, an Open Access Policy has been adopted.

The CPL service is administrated and maintained by Chalmers Library. 


\section{Title: A scale model study of parallel urban canyons}

Short title: urban canyon scale model

Maarten Hornikx* and Jens Forssén**

*Applied Acoustics, Chalmers University of Technology, SE-41296 Göteborg, Sweden. maarten.hornikx@chalmers.se

0046-(0)317728605

**Applied Acoustics, Chalmers University of Technology, Göteborg, Sweden.

This manuscript has not been submitted to any other journal

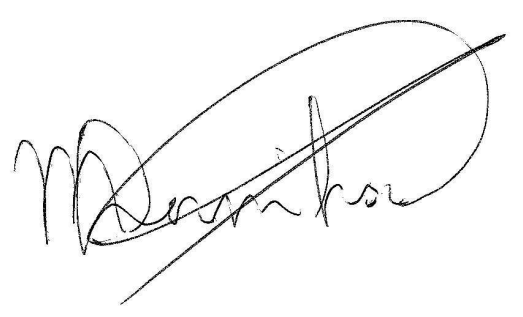




\begin{abstract}
Shielded urban areas are of importance regarding urban citizens' annoyance and adverse health effects related to road traffic noise. This work extends the existing knowledge of sound propagation to such areas by a scale model study, rather than by model calculations. The scale model study was executed for two parallel urban canyons at a 1 to 40 scale, with a point source located in one canyon. Cases with acoustically hard façades and absorption and diffusion façade treatments were investigated. To correct for excess air attenuation of the measurements, a waveletbased method has been applied. The measurement results in the shielded canyon show that, in contrast to the directly exposed street canyon, the levels and the decay times are quite constant over the length of the canyon. The energy-time curve in the shielded canyon is characterized by a rise time, which can be related to the sound pressure level. The rise times and decays can be explained by separate reflection, diffraction and diffusion processes. A closed courtyard situation enlarges the level difference between acoustically hard façades and applied façade absorption or diffusion treatments at both the directly exposed and shielded side. A comparison between measurements with two different diffusion mechanisms, horizontal and vertical diffusion, reveals that vertical diffusion yields lower levels at the shielded side compared to horizontal diffusion for the investigated situations.
\end{abstract}

PACS: 43.28.En, 43.38.Ja, 43.58.Bh, 43.58.Gn, 43.60.Hj

\title{
1 Introduction
}

Urban acoustics has been an attractive research topic for several decades. The main motive for studying this field has been the high sound pressure levels mainly due to road traffic noise, a large amount of people populating cities are exposed to [1]. Research campaigns aim to reduce these levels, and thereby the related annoyance and adverse health effects. These studies center at investigating, besides the sound excitation part, the sound propagation transfer path between source and receiver: urban sound propagation. Measures that can be taken concerning the transfer path include shielding (e.g. by a barrier), increasing diffusion (e.g. by non-specular reflections at façades) and absorption (e.g. by highly absorptive façade materials). Urban sound propagation models can classically be divided in macroscopic and microscopic models, referring to models covering a part of a city or one city unit, like a street or a square. This second group is useful for cases where short distance traffic is important and to help understanding 
what happens physically in the less precise macroscopic models. In the 60ies and 70ies, geometrical acoustics models were developed to calculate the sound pressure level in a street canyon with geometrically reflecting boundaries [2, 3, 4]. Lyon noticed the difference between calculations with models based on geometrical reflections and measurement results [5]. Since then, several models have been developed that accounted for non-specular reflections. Bullen and Fricke [6] came with a modal approach accounting for non-specular reflections. Later, the Boundary Element Method was used by Hothersall et al. [7]. Based on the assumption of diffuse reflections, the diffusion equation [8] and a radiosity based model were presented [9]. For narrow street canyons, Iu and $\mathrm{Li}$ showed that a coherent image sources model is necessary rather than an energy based model [10]. Other valuable contributions to modelling sound propagation in a street canyon can be found in references [11,12,13,14]. The knowledge of the sound field in a street canyon gained by the models has been supported by measurements. Early measurements include the work of Weiner et al. [4], and Steenackers et al. [15]. Recently, Picaut et al. presented the results of a successful measurement campaign in a single street canyon [16]. Also, scale model measurements have been conducted to show the usefulness of the developed models [10,16,17, 18, 19]. In contrast to street canyon situations, studies on squares are more rare. Kang reported on the work done in that field [20].

Among others, Kihlman pointed out that a solution to the urban noise problem lies at the presence of shielded sides like closed inneryards [21]. Access to these shielded areas has been shown to yield a positive effect on health and well-being for inhabitants of dwellings bordering such areas [22, 23]. Though, the long term levels or temporal variations in the levels at these shielded urban sides can still yield annoyance and adverse health effects. Therefore, models to predict the levels at shielded urban sides were developed. Research on the sound field at the shielded side is however not as established yet as that for the directly exposed side. Two-dimensional (2-D) wave based models have previously been developed for this purpose: the Finite Difference Time Domain method (FDTD) by van Renterghem and Botteldooren [24] and the Equivalent Sources Method (ESM) by Ögren and Kropp [25]. Also, an approach based on the parabolic equation was suggested [26]. These models predict the sound pressure level at a shielded canyon due to a sound source in a parallel street canyon. Recently, the 2.5-D ESM has been presented [27]. This model calculates the solution of a point source in the geometry of parallel canyons that are invariant along the length of the canyons. The models have previously not been compared with measurement results. Therefore, measurements of sound pressure levels and decay times at the shielded side including varying positions 
along the canyon will provide a valuable extension to the existing research results. It is in addition interesting to investigate three-dimensional (3-D) effects in order to evaluate the necessity of a 3-D prediction model. A scale model study is very suitable to accomplish such measurements. In contrast to full-scale measurements, most parameters can be controlled there, reducing the level of uncertainty. A scale model study of a point source in the geometry of two parallel canyons was therefore executed and the results are presented here. The used geometry extends the former studied cases of a single street canyon and a single barrier. Situations with acoustically hard façades (further denoted as rigid façades), façades with absorption patches applied and rigid façades with patches causing a non-specular reflection (hereon called diffusion patches) have been examined.

The aim of this work is to get new information on the sound field at the shielded canyon by comparing results with directly exposed canyon results, as well as data on the directly exposed and shielded square.

The paper is organized as follows. The next Section describes the set-up of the scale model, the materials used and the way the obtained data have been analyzed. A wavelet method has thereby been developed to correct for excess air attenuation. In Section 3 , the accuracy of the scale model results are displayed. In Section 4, the sound field at the shielded side is discussed by comparing its properties with those of the sound field at the directly exposed side. The influence of added damping (by façade absorption) and increased diffusion is compared with the case of rigid façades. In Section 5, the usability of a 2.5-D calculation model is discussed by comparing canyon results with those from a closed courtyard and situations with vertically and with horizontally applied diffusion patches.

\section{Scale model set-up and data analysis}

\subsection{The physical model and used materials}

The accuracy that can be obtained from scale model measurements increases with the chosen scale. The upper scale is however limited by practical handling of the model and the dimensions of the measurement chamber. The multiple aspects that influence the accuracy of the results - microphone, source, measurement system, excess air attenuation and materials - determined the choice of the scale and frequency range. A scale of 1 to 40 was chosen and a frequency range of the $1 / 3$-octave bands from $4 \mathrm{kHz}$ to $40 \mathrm{kHz}$ ( $100 \mathrm{~Hz}$ to $1000 \mathrm{~Hz}$ at full scale) was used. To minimize the effect of background noise 
and unwanted reflections, the measurements were carried out in the anechoic chamber of Chalmers University of Technology. A rectangular ground floor structure of $3 \mathrm{~m} \times 3$ $\mathrm{m}$ bearing the scale model was placed in this chamber.

Figure 1 shows sketches and pictures of the model as well as the used coordinate system. The geometry represents two city canyons with a single point source in one canyon. The source represents a road traffic vehicle and its height of $0 \mathrm{~m}$ is a good low frequency approximation for tyre road noise, yet breaks down at higher frequencies and for the engine noise. When considering 1/3-octave band sound pressure levels, differences with real sound source heights are not expected to be large. This is supported by the close results for two source heights in street canyon measurements of Picaut et al. [28]. The second canyon represents a shielded side, without traffic. The height of all three building rows, the street canyon widths and the central building width were chosen to be $0.5 \mathrm{~m}$ ( $20 \mathrm{~m}$ at full scale). These dimensions are representative for European city centers [29]. The scale model was as a start designed as a 2.5-D geometry. The source is placed off center in the canyon to prevent exciting one of the first modes at their position of minimum velocity level. Receiver positions were chosen over the height and length and are also shown in Figure 1. By symmetry, results along the $y$-direction, i.e. over the length of the canyon, have been found by pair-wise averaging over receivers with equal positive and negative $y$-values. When mentioning dimension, time and frequency in the results, full scale values will be used unless stated differently.

Rigid materials were chosen in the study since they yield an extreme case that gives a good understanding of the sound propagation without additional effects as diffusion and absorption. Later, these effects have been added. The ground material consisted of a chipboard plate covered with a thin layer of melamine (a plastic). Plexiglas boxes of $250 \mathrm{~mm} \times 250 \mathrm{~mm} \times 250 \mathrm{~mm}(10 \mathrm{~m} \times 10 \mathrm{~m} \times 10 \mathrm{~m}$ in reality) were used for the building blocks. The boxes had an opening at one side, which facilitated the placement of the microphone at the façade level. For the diffusion patches in the canyons, Plexiglas was used as well. Applied absorption patches consisted of $3 \mathrm{~mm}$ thick velvety felt. The positions of the absorption patches and diffusion patches are shown in Figures $1 \mathrm{~b}$ and $1 \mathrm{~h}$. Two types of diffusion treatments were investigated: cases with horizontally and vertically oriented patches. The impedance of the felt material has been determined using the excess attenuation method as is described in Appendix A. Figure 16 displays the absorption coefficient for a normal incident sound wave obtained by the method. 


\subsection{Acquisition system}

For both frequency and time domain analyses, an impulse response was desirable as the output of the measurements. This was obtained by using the MLSSA system: a measurement program that computes the impulse response from a correlation between the received signal and the known emitted source signal using the MLS technique [30]. The system is useful in the chosen frequency range. An impulse response could also be obtained using a spark type source. The repeatability in the MLS technique as well as its ease of increasing the signal to noise ratio constitute a preferable technique than by using a spark type source. A sample frequency of $133 \mathrm{kHz}$ was required (3 x highest frequency of interest) since the MLS power falls by $1.6 \mathrm{~dB}$ at $1 / 3$ of the sample frequency.

Because its rather flat frequency response and its low directionality in the frequency range of interest, an 1/8 inch condenser microphone, type B\&K 4138, was used as the receiver [31]. The microphone was mounted from within a Plexiglas box or from below the ground and positioned with its membrane in the plane of the façade or ground surface to lower the directionality and reduce the disturbing effect of the presence of the microphone and preamplifier on the measurement results. To ensure that the microphone was mounted identically at various positions of each measurement session as well as in the reference measurements, a Plexiglas box (or a ground surface patch) with the microphone mounted in it was moved for each measurement and reference measurement position.

A tweeter source with a smooth free field response in the chosen frequency range was chosen for the sound source [32]. To allow for comparison with 2.5-D ESM calculations, an omnidirectional sound source was desirable. The sound source was mounted in the ground floor below a Plexiglas plate with a circular hole to obtain such a sound field. This hole now acted as the source. A $10 \mathrm{~mm}$ hole was used for the 1/3-octave bands 4 up to $12.5 \mathrm{kHz}$ and a $3 \mathrm{~mm}$ hole was used for the bands 16 up to $40 \mathrm{kHz}$. Figure 2 shows the vertical and horizontal directionality of the source with the $10 \mathrm{~mm}$ hole at $10 \mathrm{kHz}$ and the $3 \mathrm{~mm}$ hole at $40 \mathrm{kHz}$. Measured results for the full set-up have been corrected for the source directionality if possible. The response of the loudspeaker was another important design parameter. The frequency response should be smooth to get frequency insensitive reference measurements and the impulse response short such that the impulse response of the system is unaffected. The cavity size above the tweeter source was therefore reduced as much as possible and was supplied with damping material to suppress the effect of cavity resonances. The pressure amplitudes were chosen 
such that non-linear effects could be neglected.

\subsection{Data analysis}

From the MLSSA system, the unfiltered impulse responses have been taken and analyzed in Matlab [33]. All measurement results presented in the next Sections are neither influenced by disturbing room reflections nor by a low signal to noise ratio. Postprocessing the unfiltered impulse responses from the scale model requires knowledge on aspects that scale linearly with frequency and, more important, aspects that do not scale linearly with frequency. Two effects that do not scale linearly are of relevance here: the finite surface impedance due to the acoustic boundary layer and air absorption.

In a thin layer close to a rigid boundary, the acoustic boundary layer, viscosity and heat conduction play a role in the wave field. This wave field can be decoupled in an acoustic, viscous and thermal wave, of which the latter two die out exponentially with the distance from the boundary. The wave fields together satisfy the boundary conditions, and yield a finite admittance, which adds to the admittance of the surface and can be approximated for air at $20^{\circ} \mathrm{C}$ by [34]:

$$
\beta \approx 2.01 \cdot 10^{5}(1-i) \sqrt{f}\left[\sin ^{2} \theta+0.48\right]
$$

where $\theta$ is the angle of incident sound wave with the normal to the surface. The equation shows the non-linear behaviour in frequency. Equation (1) has with satisfying agreement been verified by scale model measurements [35]. Figure 3 shows the calculated level relative to the free field level with a source and a receiver above a rigid surface with and without including the effect of the acoustic boundary layer. The calculation has been done using a ray model with a spherical wave reflection coefficient. According to equation (1), the effect of the boundary layer increases with frequency and angle of incidence. In the audible acoustics range, the boundary layer effect is of negligible importance, but it is not at the high frequencies of the scale model measurements. Since the admittance due to the boundary layer effect is small compared to the admittance of other materials having finite impedance, the boundary layer effect is in principle only of interest in cases of sound propagation over rigid surfaces. It is hard to correct for this finite impedance in post-processing the measured data and the effect of the acoustic boundary layer admittance has not been taken into account here. When using the measurement data for a comparison with model calculations, the effect of the acoustic 
boundary layer should be included there.

The second non-linear effect is the attenuation of sound waves by air. The attenuation is mainly caused by classical absorption (with a power loss proportional to $f^{2}$ ), and by relaxation and compression effects of nitrogen and oxygen molecules (with a power loss non-linearly proportional to $f$ ) [36]. A large air absorption may result in a low signal to noise ratio, especially for long impulse responses. Classical air absorption is hard to avoid, whereas changing the constitution of air can influence the second effect. Considering Figure 4 for the relevant frequencies of the scale model $(4 \mathrm{kHz}-45 \mathrm{kHz})$, it is worth reducing the relative humidity of the air towards a humidity of $0 \%$. The facilities to achieve these humidities were not available. The measurements have been corrected for the excess air attenuation. This has been done towards no air attenuation. Several methods to correct for excess air attenuation in scale models were published before (see e.g. [16, 37, 38, 39]). These methods are based on a short-time Fourier transform or by small band filtering the time signal. The drawback of these methods regarding correcting a signal for a factor depending on time and frequency is inherent in the Fourier transform pair: strictly, only a correction in time or frequency is possible. An alternative is to apply the wavelet technique, which transforms a time signal into the time-scale plane, where the signal is localized in both scale (which is proportional to the frequency) and time. An ideal localization in frequency and time is however not possible due to limited duration of the frequency-bandwidth product of a signal [40]. A continuous wavelet transform has here been applied to the measured time signal. In the obtained time-scale plane, the signal is corrected for the time and frequency dependent excess air attenuation calculation according to ISO 9613-1:1993. A reconstruction returns the original signal, corrected for the excess attenuation. Appendix B describes the details and accuracy of this method.

The sound field in the canyons has been evaluated regarding the level and decay time, since both are assumed to be related to the rate of annoyance. Pressure values used to calculate the levels have been obtained by a fast Fourier transform of the impulse responses. Reference receiver positions were located in the street canyon where the first part of the impulse response was used to obtain the reference sound pressure level. There are three types of levels that have been used throughout the paper. The first is the excess attenuation level, i.e. the level relative to the level without any objects:

$$
L_{E A}(f)=20 \log \left|\frac{p_{\text {meas }}(f) r_{\text {meas }}}{p_{\text {ref }}(f) r_{\text {ref }}}\right|
$$


where $p_{\text {meas }}(f)$ is the complex pressure at the receiver position, $r_{\text {meas }}$ the line of sight source-receiver distance, $p_{\text {ref }}(f)$ the complex pressure at a reference position without obstacles and $r_{r e f}$ the line of sight source-reference receiver distance. Second, the sound pressure level, relative to the free field level:

$$
L_{\text {refree }}(f)=20 \log \left|\frac{2 p_{\text {meas }}(f) r_{\text {meas }}}{p_{\text {ref }}(f) r_{\text {ref }}}\right|
$$

The factor 2 is introduced since the source was located at the ground surface for the reference measurement. Third, the sound pressure level relative to the free field level at one meter from the source:

$$
L_{\text {refree }, 1 m}(f)=20 \log \left|\frac{2 p_{\text {meas }}(f)}{p_{\text {ref }}(f) r_{\text {ref }}}\right| .
$$

This level is introduced to have the same reference level for various receiver positions. To calculate a broad band level, levels have been A-weighted and weighted for a road traffic noise spectrum:

$$
L_{A}=10 \log \left(\frac{\sum_{i=1}^{11} B_{i} 10^{\frac{L_{i}+A_{i}+C_{i}}{10}}}{\sum_{i=1}^{11} B_{i} 10^{\frac{A_{i}+C_{i}}{10}}}\right)
$$

where $A_{i}$ and $C_{i}$ are the $A$-weighting and traffic spectrum weighting for the $1 / 3$-octave band $i$, corresponding to the bands with center frequencies $100 \mathrm{~Hz}-1000 \mathrm{~Hz}$. Finally, $B_{i}$ is the 1/3-octave band bandwidth. For the road traffic noise spectrum, a distribution of $90 \%$ light and $10 \%$ heavy vehicles with a speed of $50 \mathrm{~km} / \mathrm{h}$ has been chosen. The traffic spectra have been taken from Danish measurement data [41].

To investigate the decay properties of the signals, the unfiltered impulse responses have been filtered by a 1/3-octave band filter. When the bandwidth-time product of an impulse response is small, the impulse response is sensitive to be influenced by the impulse response of the used filters. Because of its short impulse response, the wavelet transform with the Morlet mother wavelet also used for the correction of excess air attenuation has been used as a 1/3-octave band filter here (with $\omega_{0}=6$, see Appendix B) [42]. The parameter used to quantify the decay of the sound field is the decay time $T 10$. Section 4.1 describes how the $T 10$ has been determined in the directly exposed and shielded canyons. 


\section{Accuracy of the scale model measurements}

To get insight in the errors of the scale model measurement results, measurement setups with a single thin barrier and single thick barrier were studied at first, see Figure 5. The source was positioned at $(9,0,0)$ and the receiver positions were at the shielded side at positions $y=0 \mathrm{~m}$ and $y=40 \mathrm{~m}$, and for two or three different heights according to the coordinate system of Figure 1. Figure 5 shows $L_{\text {refree,measured }}(f)$ compared with $L_{\text {refree,calc }}(f)$ using the diffraction model of Pierce [43]. Measurement results have been corrected for source and microphone directionality by making use of the sourcebarrier angle, barrier-receiver angle and the measured source and receiver directionalities. The single screen material was equal to the ground material, and Plexiglas boxes were used for the thick barrier. The results show that most of the measurements agree with the calculated results within $2 \mathrm{~dB}$. The agreement is worst at the lowest 1/3-octave bands, where deviations could be caused by possible leakage through the barrier or radiation by the barrier material. Due to the many different angles of sound wave incidence from multiple reflections in the situation of parallel canyons, source and microphone directionality cannot accurately be corrected for. Some deviations can therefore be expected at the highest frequencies. Previous scale model studies for similar geometries and scales also displayed the limited accuracy that can be obtained from scale model studies in 1/3-octave bands [10,16].

The scale model was set up as a 2.5-D model, yet the length of the buildings in the scale model is finite. Figure 6 shows a comparison of a calculation with a finite barrier, calculated by a time domain formulation by Svensson [44] and an infinite barrier calculated with the model of Pierce [43]. The receiver is in the shadow zone of the barrier and horizontal diffraction around the barrier has not been included. The results show that the effect of the finite barrier length is small and that the error is smallest at higher frequencies, and hence shows that the scale model is good a representation of infinitely long parallel canyons.

\section{The sound field in the parallel canyons}

Several authors reported on the behaviour of the sound field in the directly exposed street canyon before (see the Introduction for references). The directly exposed street canyon results of the current scale model study will be discussed along with these literature results and serve as a reference to place the shielded canyon results in perspective. In this Section and Section 5, the 1/3-octave band levels and decay times $T 10$ are the tools 
of comparison. The level results have to be interpreted with the shown measurement accuracy of Section 3 in mind.

\subsection{Directly exposed street canyon}

\subsubsection{Sound pressure levels}

Figure 7 shows the measured $L_{\text {refree, } 1 \mathrm{~m}}$ for all receiver heights and façade types. The plots are a function of the $y$-distance and frequency. When regarding Figure 7, we notice that the levels in the directly exposed street canyon decrease over the $y$-distance of the street canyon. The decrease is approximately $3 \mathrm{~dB}$ per distance doubling for the rigid façades case. This is similar to a line source decay, which would be obtained in the limit of a narrow street canyon flanked by high buildings. Over frequency, the levels for the rigid façades case are quite constant, indicating that the absorption coefficients are constant over the frequency.

Figure 8 shows the level difference between receiver positions at $z=5 \mathrm{~m}$ and $z=15$ $\mathrm{m}$ for the various cases with rigid façades, façades with applied absorption patches and façades with diffusion patches (horizontally or vertically oriented). The level at $z=5 \mathrm{~m}$ is larger than the one at $z=15 \mathrm{~m}$ closer to the source due to the importance of the direct field. At a further $y$-distance from the source, the levels at $z=5 \mathrm{~m}$ and $z=15 \mathrm{~m}$ are closer. This behaviour holds for all cases and was also found by Kang [9]. The larger difference in the absorption case for a small $y$-distance is caused by the high frequency results at receiver positions at $z=5 \mathrm{~m}$ that have high values (see the left part of Figure 8).

Figure 9 shows the level difference over distance and frequency between rigid façades and the other cases. The results have been averaged over $z=5 \mathrm{~m}$ and $z=15 \mathrm{~m}$. The level difference increases with distance for all cases, since higher order reflections are of more importance at a larger distance from the source. This was also shown by Kang ([46], Figure 11). The level difference between rigid façades and applied absorption patches over frequency is obvious, clearly governed by the frequency dependence of the absorption material. The level difference between rigid façades and diffusion patches is more subtle. The results agree with previous ones in that the levels with diffusion patches close to the source are higher than the levels with rigid façades, whereas at a larger $y$-distance, the levels with diffusion are lower than the level with rigid façades ([46], Figure 6). 


\subsubsection{Calculation of reverberation time $T 10$}

Some extra attention will be paid to the calculation of $T 10$ here. A decay time in general, and the $T 10$ in particular here, is determined from the decay of the sound field after a sound source, turned on a long time ago, has been turned off. The T10 can be calculated from a single impulse response using Schroeder's backwards integration method in order to determine the reverberation time (Schroeder's curve, [47]). According to the standard ISO 3382, the relation between the decay of the sound pressure level and the time should be a straight line. The $T 10$ is then the best fitted straight line between the decay of the sound level from $-5 \mathrm{~dB}$ to $-15 \mathrm{~dB}$, extrapolated to $-65 \mathrm{~dB}$. When the sound field is diffuse, the decay of the energy-time curve (the squared impulse response) is theoretically a straight line when plotted as a level and equals the shape of the decay of Schroeder's curve. However, when the sound field is not diffuse, as in our case, the decay of the energy-time curve is not equal to the decay of the sound field as defined for the T10. Thus, Schroeder's curve has to be taken from an impulse response to obtain the true decay. A problem arises when the measured impulse response of a non-diffuse field is not complete: the Schroeder curve of such an impulse responses differs in shape from the complete Schroeder curve. The here measured impulse responses have to be truncated since correction for air absorption starts blowing up the background noise at the tail of the impulse response (especially for the highest 1/3-octave bands). Only the part of the impulse response unaffected by this correction has been taken to calculate the T10. In order to calculate the $T 10$, the 1/3-octave band Schroeder curves of the truncated measurements have been fitted by Schroeder's curves calculated by an Image Sources Model (ISM). The absorption coefficient of the façades has been used as the fitting parameter for all types of façades. The number of reflections included in the ISM corresponds to the time length of the truncated measurement. The ISM and measurement curve were fitted up to a distance were the Schroeder curves start to drop quickly, see Figure 10. The ISM with the fitted absorption coefficient has then been used to compute the $T 10$ s by extending the number of reflections up to a value that guaranteed convergence.

\subsubsection{Reverberation time $T 10$ results}

Due to the sensitivity of the $T 10$ calculations in the case with rigid façades (the small amount of damping leads to large T10s), the averaged T10s are presented in Figure 11.

The average $T 10$ s for $z=5 \mathrm{~m}$ and $z=15 \mathrm{~m}$ are in Figure 11a shown for the case with rigid walls. The $T 10$ at $z=15 \mathrm{~m}$ is longer than the $T 10$ at $z=5 \mathrm{~m}$ for a small 
$y$-distance and vice versa for a large $y$-distance. This holds for all cases (not shown in the Figure here) and is due to the influence of the direct field. At $y=0 \mathrm{~m}$, the level difference between direct and reflected wave fields is larger due to the path length difference for $z=5 \mathrm{~m}$ than for $z=15 \mathrm{~m}$. At $y=40 \mathrm{~m}$, this level difference is larger for $z$ $=15 \mathrm{~m}$, since higher order reflections have a lower amplitude due to the finite height of the street canyon.

Figure $11 \mathrm{~b}$ shows the $T 10$ s averaged over $1 / 3$-octave bands and receiver height positions. All T10s increase with distance (also found before in [16] and [46]). The difference in $T 10$ between rigid façades and diffusion patches is remarkably large when having their small level difference in mind. This emphasizes that the direct contribution determines the levels for a large part in the directly exposed street canyon.

Figure $11 \mathrm{c}$ shows the $T 10$ s averaged over all positions. The large $T 10$ difference at low frequencies between the diffusion patches and the rigid façades cases is even more remarkable, since the applied diffusion patches have depths that are much smaller than the wavelengths at the low frequencies $(\lambda / 15$ at $100 \mathrm{~Hz})$. It may be explained by the effect of multiple reflections: the diffuse part of a multiple reflected sound wave is dominating over the specular reflected part even if the diffuse reflection part for a single reflection is small. The frequency dependence of $T 10$ for the absorption case shows a correlation with the absorption coefficient of the applied felt. The higher $T 10$ for absorption compared with horizontally oriented diffusion patches over the $y$-distance in Figure $11 \mathrm{~b}$ is caused by the dominance in the low frequencies for the absorption case. The frequency dependence for the rigid case (see Figure 11c) again shows the dominance of the direct contribution to the level, since the levels did not show this frequency dependent trend.

\subsection{Shielded canyon}

\subsubsection{Sound pressure levels}

In the shielded canyon, the level difference over the $40 \mathrm{~m}$ length of the canyon is small (see Figure 7); the amplitude reduction due to spherical spreading is compensated for by the smaller diffraction angle. Over frequency, a clear level decrease is visible for all cases. This decrease is, for the rigid façades and diffusion patches, caused by the higher shielding for high frequencies (diffraction effect). The frequency dependence in the absorption case is governed by both diffraction and absorption effects.

In Figure 8, we notice that the level differences between $z=5 \mathrm{~m}$ and $z=15 \mathrm{~m}$ are quite constant. This level difference is largest for the absorption case, since there, the 
multiple reflected sound waves have more been damped before they reach the lower receiver position.

Figure 9 shows the level differences between the case with rigid façades and the other cases. We notice that the level difference over distance is also rather equal. Over frequency, Figure 9b, the level difference is rather equal regarding diffusion as well. For the investigated geometry and source and receiver positions, the level difference in the shielded canyon is larger than the level difference in the directly exposed street canyon. This is caused by the fact that the higher order reflections are of more importance in the shielded canyon. From Figure 9b, we notice that the levels with absorption patches are lower than the levels with diffusion patches for the higher frequencies. The effect of diffusion is here equal to the effect of the applied absorption patches with an absorption coefficient of around 0.2.

From calculations with the FDTD method using a coherent line source, van Renterghem et al. found a level difference between rigid façades and façades with an absorption coefficient of 0.33 (for normal wave incidence) of around $20 \mathrm{~dB}$ in the shielded canyon [48]. Their canyons had a $10 \mathrm{~m}$ x $10 \mathrm{~m}$ wide cross section and were $100 \mathrm{~m}$ apart. The use of balconies (causing diffuse reflections) could give a gain of 5-10 dB for all 1/3octave bands compared to a situation without balconies. The level differences found here are of the same order of magnitude.

\subsubsection{Rise time}

The energy-time curves in the shielded canyon have a different shape than the ones in the directly exposed street canyon: after the first arrival at time $t_{0}$, the energy increases until a certain time $t_{1}$, after which the energy decreases, see Figure 12 . The time $t_{s}=t_{1}-t_{0}$ is here called the rise time. The rise times have been calculated per measurement position and 1/3-octave band and averaged results are plotted over $y$-distance, frequency and for three measurement heights: $z=0 \mathrm{~m}(x=49 \mathrm{~m}), z=5 \mathrm{~m}$ and $z=15 \mathrm{~m}$, see Figures $13 \mathrm{a}, 13 \mathrm{~b}$ and $13 \mathrm{c}$. The rise times show clear trends:

- The rise time is rather constant over the length of the street canyon;

- The rise time decreases with receiver height;

- The rise time increases with frequency, except for absorption patches.

In the case of absorption patches, the rise time does not increase with frequency, due to the increasing absorption coefficients with frequency. 
The energy-time curve at the shielded side can be explained using the following ray model approach. Consider the cross section in Figure 14. The impulse response can be approximated by the convolution of the impulse responses from the source to diffraction corner 1 and from diffraction corner 2 to receiver point, weighted by a diffraction factor and phase and amplitude correction. The dashed-dotted line in Figure 14 shows the energy-time curve for the sketched case when the diffraction coefficients would have unity values, i.e. no screening. The absorption coefficient of the façades has been set to $5 \%$, and a time integration of $50 \mathrm{~ms}$ has been applied. The thin lines in Figure 14 show the diffraction coefficients for $100 \mathrm{~Hz}$ and $1000 \mathrm{~Hz}$. The diffraction coefficient increases with distance since the diffraction angle decreases with increasing order of reflection. The product of the dashed-dotted curve and a diffraction coefficient curve gives the shape that we found from our measurements (Figure 12). Depending on the position of the source and receiver (and thus the shape of the diffraction coefficient curve), the shape of the energy-time curve after its maximum value will be concave, straight of convex. Due to the fact that the diffraction coefficient for higher frequencies increases slower with time in the early part, the rise time will be larger for $1000 \mathrm{~Hz}$ than for $100 \mathrm{~Hz}$. This is in accordance with the measurements. When a higher absorption coefficient would be assigned to the façades, the diffraction coefficient is unchanged, yet the decays in the separate canyons are faster. The rise time will then be shorter. The rise time is thus correlated to the level: a longer rise time (smaller absorption coefficient) yields a higher level. This is confirmed by the rise time differences between the rigid façades case and the other cases.

\subsubsection{Reverberation time $T 10$}

Since the levels in the shielded canyon are low compared to the levels in the directly exposed street canyon, the signal to noise ratio in the shielded canyon is lower and the influence of the correction for excess attenuation is larger. This implicated that the useful length of the impulse response was too short to determine the $T 10$ in the same way as done for the directly exposed canyon. To have an impression of the decay of the sound field after the rise time, the $T 10$ has been calculated using the energy-time curve for the lowest $1 / 3$-octave bands $(100 \mathrm{~Hz}-315 \mathrm{~Hz})$. Figure 13 shows the averaged T10 over the length of the canyon. Again, the decay times are quite constant over the length of the canyon. The $T 10$ for rigid façades is clearly larger than for the other cases, which do not differ much. 


\section{Three-dimensional geometrical effects in canyons}

The 2.5-D ESM prediction model is not able to predict 3-D geometrical effects. For urban sound propagation, 3-D geometrical effects like a closed courtyard situation and vertically oriented diffusion patches are typical. These cases were chosen to investigate the difference between a 2.5-D and 3-D geometry.

\subsection{Canyon versus closed courtyard}

\subsubsection{Directly exposed side}

The results for a source and receiver in a closed courtyard are compared with the ones of the directly exposed street canyon. The closed courtyard has the dimensions $20 \mathrm{~m} \mathrm{x}$ $20 \mathrm{~m}$ x $20 \mathrm{~m}$, see Figure 1 . Figure 15 shows the level differences $L_{A \text {,courtyard }}-L_{A \text {,canyon }}$ in $\mathrm{dB}(\mathrm{A})$ and the decay time differences $T 10_{\text {courtyard }}-T 10_{\text {canyon }}$ at $y=0 \mathrm{~m}$ for $z=$ $5 \mathrm{~m}$ and $z=15 \mathrm{~m}$ for the various cases. Schroeder's curve for a street canyon and closed courtyard are shown in Figure 10. The number of reflections arriving at the receiver within a certain time slot is almost constant over time in the street canyon, whereas the number increases with time in the closed courtyard. The energy decay is thus much slower in the closed courtyard. The concave decay of the sound energy over time in a street canyon was also shown by Steenackers [15] and Kang [9]. The Schroeder curve difference between street canyon and closed courtyard is retrieved in the level difference and the averaged $T 10$ difference, also shown in Figure 15. The closed courtyard $T 10$ s for rigid façades are similar to the calculated reverberation time by Kang for a larger square $50 \mathrm{~m}$ x $50 \mathrm{~m}$ x $20 \mathrm{~m}$ [20]. Since the higher order reflections are of more importance in the closed courtyard case than in the street canyon case, the level differences between the rigid façades case and the other cases increase compared to the street canyon case. The level difference is larger for $z=15 \mathrm{~m}$, whereas the averaged $T 10$ difference is largest for $z=5 \mathrm{~m}$.

\subsubsection{Shielded side}

At the shielded side, a closed courtyard was built as well. The directly exposed side was still kept as a street canyon, see Figure $1 \mathrm{~h}$. All receiver positions were at $y=0 \mathrm{~m}$. Results can be found in Figure 15 and show that also at the shielded side, the closed courtyard levels are higher than the canyon levels. It is however much less obvious than at the directly exposed side. Compared to a canyon situation, a closed courtyard situation increases the sound pressure level reduction due to of absorption and diffusion relative 
to the rigid façades case. The negative values in the absorption case can be concluded to be a measurement error. Whereas the rigid façades case displays an increase in level and $T 10$ for the courtyard case, the differences for the other cases are negligible concerning $T 10$ and within the range of uncertaincy concerning the level. Note that the difference between street canyon and closed courtyard at the shielded side is not studied for a source position different from $y=0 \mathrm{~m}$. The shielding due to the diffraction effect would then increase for the shielded closed courtyard compared to the canyon. On the other hand, the rays are horizontally trapped once the sound energy has reached the closed courtyard.

\subsection{Vertical diffusion versus horizontal diffusion}

\subsubsection{Directly exposed side}

The second effect not captured by 2.5-D model is when vertically oriented façade diffusion patches are applied, creating horizontal diffusion. For such a case, the same amount of patches was applied as in the case of horizontally oriented façade diffusion patches (40\% of the façades were covered), yet now they were mounted vertically oriented. The effect of horizontal diffusion (vertically oriented patches) is investigated by comparing the results with the vertical diffusion case (see Figures 8 and 9). A similar level difference between $z=5 \mathrm{~m}$ and $z=15 \mathrm{~m}$ as well as a similar level difference with the rigid façades case is found for both types of diffusion. The degree of diffusion could be decisive for this similarity. The $T 10$ with vertically oriented diffusion patches is higher than with horizontally oriented patches. This can be attributed to the type of diffusion mechanism: when the elements are oriented horizontally, more energy is scattered out of the street canyon than in the case with elements oriented vertically. The $T 10$ is therefore higher in the latter case. This is even more obvious in the closed courtyard case, see Figure 15, where the difference in $T 10$ is larger for the vertically oriented patches than for the horizontally oriented ones.

\subsubsection{Shielded side}

At the shielded side, the levels with vertically oriented patches are higher than with horizontally oriented patches, both over distance and frequency (see Figure 9), whereas the level difference between $z=5 \mathrm{~m}$ and $z=15 \mathrm{~m}$ is rather similar (see Figure 8 ). The effect of the level difference is also indicated in the rise time plots, Figure 13, where the rise times for horizontal diffusion are longer than the rise times for vertical diffusion. 
Vertical diffusion is thus shown to be more effective in reducing levels at the shielded side than horizontal diffusion. It can be explained by the fact that vertical diffusion (horizontal patches) leads to a more diffuse sound field in the $x-z$ plane that horizontal diffusion. In the shielded closed courtyard, the level difference between the two types of diffusion is similar to the canyon case.

\section{Conclusions}

A 1 to 40 scale model of parallel urban canyons was built. It has been shown that this model represents a two-dimensional (2-D) situation of infinitely long canyons. This geometry, with a point source, is called 2.5-D if it is invariant along the canyons. The measurements have been made for rigid façades, horizontally oriented façade absorption patches and horizontally oriented façade diffusion patches. A monopole source was located in one street canyon and receiver positions were located over the canyon length of both the directly exposed street canyon and the parallel shielded canyon. Since, according to the authors' knowledge, this is the first extensive measurement campaign for a shielded canyon, the measurement results also give new insight in the sound field there.

\subsection{Sound pressure levels in the shielded courtyard}

The sound pressure level and the reverberation time $T 10$ are, in contrast to the values at the directly exposed side, quite constant over the length of the canyon, indicating the importance of taking into account distant sources when predicting noise levels. This holds for all investigated cases. The level differences between rigid façades and applied absorption or diffusion patches are larger in the shielded canyon than in the directly exposed street canyon. It should be noted however, that using rigid façades for the reference case can over predict the effect of noise mitigation measures compared to using real existing building façades.

\subsection{Decay times in the shielded courtyard}

Energy-time curves have been obtained, which show a distinct difference between the directly exposed and shielded canyon. Whereas the energy-time curve in the directly exposed street canyon decreases after the first arrival, the curve in the shielded canyon first increases to a maximum, and thereafter decreases. The time from the first arrival 
to the maximum level, the rise time, has been shown to be related to the level. The rise time is also constant over the length of the canyon, yet decreases with receiver height and increases with frequency, which has also been explained by separate reflection and diffraction processes.

\subsection{Three-dimensional geometrical effects in canyons}

Besides canyons, closed courtyard situations have been investigated and compared to street canyon results. A clear increase of the level and $T 10$ is visible at the directly exposed side for the closed courtyard. The increase is present, yet less obvious at the shielded side. With the rigid façades case as a reference, absorption and diffusion façade treatments at a shielded closed courtyard reduce the levels more than in a canyon. Only one source position was however used for the closed courtyard situations. Since existing prediction methods are 2.5-D (or 2-D) and only can capture vertical diffusion effects, a comparison between horizontal and vertical diffusion has been made from the measurement results. In the directly exposed street canyon, the levels are similar whereas the $T 10$ with horizontal diffusion is slightly larger than the $T 10$ with vertical diffusion. At the shielded side however, the levels with vertical diffusion are significantly lower than with horizontal diffusion. The rise times indicate this difference as well. When using a 2.5-D model for urban canyons, one thus has to keep in mind that façade treatments could be more effective in a closed courtyard situation than in the calculated canyon case. Also, the effect of diffusion could be different from reality, since no horizontal diffusion can be modelled with the 2.5-D model.

\section{Acknowledgements}

The work behind this paper has been funded by the Swedish Foundation for Strategic Environmental Research (MISTRA). The authors would like to thank Wolfgang Kropp for his ideas and fruitful discussions.

\section{A Material impedances determined by the excess atten- uation method}

The impedance of the used materials in the scale model study has been determined by the excess attenuation method. The excess attenuation was obtained from the free field 
complex frequency response of a monopole sound source and the complex frequency response of the same geometrical source-receiver configuration, but now in the presence of the material under investigation. The source as mounted in the ground floor was used, creating approximately an omnidirectional sound field over an half-sphere (see Section 2.2). The measured excess attenuation level is:

$$
L_{E A, \text { meas }}=20 \log \left|\frac{p_{\text {mat }, \text { meas }}(f)}{p_{\text {ref,meas }}(f)}\right|,
$$

where $p_{\text {mat,meas }}$ is the measured complex pressure in the presence of the material under investigation and $p_{\text {ref,meas }}$ is the measured complex pressure in the absence of the material under investigation. The excess attenuation levels are at the other hand calculated using $p_{\text {ref,calc }}=\frac{e^{i k r_{1}}}{r_{1}}$ and $p_{\text {mat, }, \text { alc }}=\frac{e^{i k r_{1}}}{r_{1}}+Q \frac{e^{i k r_{2}}}{r_{2}}$, where $k$ is the wavenumber, $r_{1}$ is the direct source-receiver distance, $r_{2}$ the image source-receiver distance in the presence of the material under investigation and $Q\left(f, \theta, Z_{n}\right)$ the spherical wave reflection coefficient implemented according to Chien and Soroka [49]. This is a function of the frequency $f$, angle of sound wave incidence $\theta$ and the normalized surface impedance $Z_{n}$ :

$$
Z_{n}=\frac{Z_{\text {material }}}{\cos \left(\theta_{m}\right) Z_{\text {air }}}
$$

where $\theta_{m}$ is the propagation angle in the material relative to the normal of the surface and $Z_{\text {material }}$ and $Z_{\text {air }}$ are specific impedances. Since the felt material is mounted on a hard backed surface (Plexiglas), the impedance model becomes [50]:

$$
Z_{n, \text { hardback }}=i Z_{n} \cot \left(k_{1} d \cos \left(\theta_{m}\right)\right) \text {, }
$$

where $k_{1}=k n$ is the wave number in the felt layer, with $n$ the refraction index, $\theta_{m}$ equal to $\arccos \sqrt{1-\frac{1}{n^{2}}+\frac{\cos ^{2}(\theta)}{n^{2}}}$ and $d$ the thickness of the felt layer. Felt is a porous material. Several impedance models have been developed for porous materials with a varying number of physical parameters included. An extensive model, the four material parameter model developed by Attenborough [51], has been used here. This model includes material flow resistivity, porosity, tortuosity and the standard deviation of pore 
size distribution. The normalized surface impedances $Z_{n}$ are derived by a minimization procedure of the following function using the Nelder-Mead Simplex Method, which is a direct search method that does not make use of gradients [52]:

$$
X=\sum_{i=89}^{i=1125}\left|L_{E A, \text { meas }}(i)-L_{E A, \text { calc }}(i)\right|
$$

The algorithm is an optimization over the whole frequency region of interest where the set of four parameters is fitted to get the minimum value of $X$. Figure 16a shows the measured excess attenuation and the calculated excess attenuation using the fitted results. In Figure 16b, the found absorption coefficient for a wave incident in normal direction to the felt material is plotted. The third part of the Figure displays the way the microphone was mounted during the measurements. For the Plexiglas and the ground material, the absorption coefficient for normal wave incidence was found to be lower than 0.05 for all frequencies of interest.

\section{B Excess air attenuation correction using the continu- ous wavelet transform method}

\section{B.1 The continuous wavelet transform}

Similar to the Fourier transform, the wavelet transform decomposes a signal onto a set of functions, a basis. In the wavelet transform, these functions all stem from a mother function, the mother wavelet. In contrast to the Fourier transform, the time signal is not transformed to separate frequencies, yet to coefficients centered on a certain time and scale (related to the frequency). The continuous wavelet transform is used, which has no restriction of scales. The continuous wavelet transform (CWT) [53]:

$$
F(a, s)=\int_{-\infty}^{\infty} p(t) \frac{1}{\sqrt{s}} \overline{\psi\left(\frac{t-a}{s}\right)} \mathrm{d} t
$$

where $t$ is the time, $p(t)$ the time signal, $a$ the translation time, $s$ the scale factor, $F$ the wavelet coefficients and the overbar denotes the complex conjugate. The mother wavelet $\psi\left(\frac{t-a}{s}\right)$ is thus scaled and translated in time during the transform: the daughter wavelets. The coefficient before the wavelet function $s^{-1 / 2}$ normalizes the energy 
content of the daughter wavelets. The mother wavelet used here is the Morlet wavelet, which is one of the most common wavelets:

$$
\psi(\eta)=e^{i \omega_{0} \eta} e^{-\eta_{0}^{2} / 2}
$$

where $\eta$ is the non-dimensional time and $\omega_{0}$ the non-dimensional frequency. The coefficient $\omega_{0}$ determines the width of the localization of the transformed signal in the time and the frequency domain; the larger $\omega_{0}$, the worse the time localization yet better the frequency localization. A value of 20 has been used here. The Morlet wavelet is a complex function, which implies that phase and amplitude information of the signal is kept in the transformed domain. Since the representation in the transformed domain entails that spectral energy is also present for wavelet coefficients outside the relevant frequency range, the smallest and largest scales used in the transform should be outside the frequency range of the signal. It is convenient to use logarithmically spaced scales $s_{j}=s_{0} 2^{j \delta s}$, where $j$ are integer numbers and a value of 0.1 will be used here for $\delta s$. The continuous wavelet transform of a measured signal is calculated in the frequency domain, where the convolution is replaced by a multiplication. The wavelet coefficients are then obtained by an inverse Fourier transform of the product of the Fourier transformed signal and daughter wavelet [54]:

$$
F(a, s)=\sum_{k=0}^{N-1} P(k) \sqrt{\frac{2 \pi s}{\delta t}} \overline{\psi\left(s \omega_{k}\right)} e^{i \omega_{k} n \delta t},
$$

with :

$\omega_{k}=\left\{\begin{array}{rll}\frac{2 \pi k}{N \delta t} & \text { for } \quad k \leq \frac{N}{2} \\ \frac{-2 \pi k}{N \delta t} & \text { for } \quad k>\frac{N}{2}\end{array}\right.$

$P(k)=$ Fourier transform of the time signal $p(t)$.

Figure 17 a shows a typical measurement signal in an urban street canyon with source and receiver in the same street canyon. The signal displays the multiple reflections in a street canyon. Figure $17 \mathrm{~b}$ shows the wavelet transformed signal in the time-frequency plane. Figure 17c shows a part of the energy-time curve of the signal and the wavelet representation, a weighted summation over all scales [54]. Figure 17d shows a part of the Fourier and wavelet power spectrum, the summation of the squared wavelet coefficients over time. Both Figures $17 \mathrm{c}$ and $17 \mathrm{~d}$ show that the wavelet power spectrum and 
wavelet energy-time curve are a smoothed representation of the real power spectrum and energy-time curve.

\section{B.2 Excess air attenuation correction}

Since the energy content at a certain position in the time-scale plane does not have a perfect localization, it is not possible to exactly correct for the excess air attenuation. The correction is calculated as a factor according to the International Standard ISO 9613-1:1993(E) with a frequency and time corresponding to the center frequency and time of the wavelet coefficient. Since the correction is linear with the energy in time, the time correction is a power of the correction factor per time sample $c$. The corrected wavelet coefficients, $F_{\text {cor }}(n \delta t, s)$, become:

$$
F_{\text {cor }}(n \delta t, s)=F(n \delta t, s) c^{n}(s) \text {. }
$$

\section{B.3 Reconstruction}

Since the continuous wavelet transform is not based on an orthogonal basis, the transform is redundant and a reconstruction is not perfect. Farge has however shown that the redundancy of the CWT allows for reconstructing the signal using a completely different wavelet function, of which the delta function is the easiest [55]. The reconstruction will be an approximation of the original signal. The used reconstruction equation is [54]:

$$
f(n \delta t)=\frac{\delta j}{C_{\delta}} \sum_{j=0}^{J} \sqrt{\frac{\delta t}{\delta s_{j}}} \Re\left(F_{c o r}(a, s)\right),
$$

where $J$ the total number of scales used, $\delta j$ the weighting of scales, $C_{\delta}$ the reconstruction factor of a delta-function and $\sqrt{\frac{\delta t}{\delta s_{j}}}$ the removal of the energy normalization. The accuracy of the reconstruction is displayed for a synthesized signal created from the frequency content of a measured signal. Figure 18a, 18b and and 18c show the created undamped and damped signal and its frequency content which lies within the frequency 
content of a measurement signal in the scale model. The signal was composed by frequencies with a random phase. Air attenuation has in figure $18 \mathrm{~b}$ been applied for $T=$ $20^{\circ} \mathrm{C}$ and $R H=30 \%$, which are typical conditions during scale model measurement. The calculated attenuation loss by air attenuation is shown in Figure 18d. Figure 18e shows the phase error between original and reconstruction of the damped signal. Finally, Figure 18f shows the levels of the signals. The first and second bar show the level of the undamped signal of Figure 18a and the damped signal corrected by the wavelet method. The third and fourth bar denote the level of the damped signal of Figure 18b and the level of the damped signal when a wavelet forward and inverse wavelet transform have been applied without a correction. The introduced errors are small.

Note that the presented way to correct for excess attenuation does not pretend to be superiour over the former presented methods, since a perfect time-frequency localization is not possible. The method does however have the advantage over the former methods that the time-frequency resolution varies with frequency and is generated implicitly with the method (no choices of filter or window widths have to be made).

\section{References}

[1] Stanners, D., Bordeau, P. (Eds.): Europe's environment. European Environment Agency. Copenhagen, Denmark (1995).

[2] Davies, H.G.: Noise propagation in corridors. J. Acoust. Soc. Am. 53 (1973) 1253-1262.

[3] Lee, K., Davies, H.G., Lyon, R.H.: Prediction of propagation in a network of sound channels, with application to noise transmission in city streets. Report, Acoustics and Vibration Laboratory, Massachusetts Institute of Technology (1974).

[4] Weiner, F.M., Malme, C.I., Gogos, C.M.: Sound propagation in urban areas. J. Acoust. Soc. Am. 37 (1965) 738-747.

[5] Lyon, R.H.: Role of multiple reflections and reverberation in urban noise propagation. J. Acoust. Soc. Am. 55 (1974) 493-503.

[6] Bullen, R., Fricke, F.: Sound propagation in a street. J. Sound Vib. 46 (1976) 33-42. 
[7] Hothersall, D.C., Horoshenkov, K.V., Mercy, S.E.: Numerical modelling of the sound field near a tall building with balconies near a road. J. Sound Vib. 198 (1996) $507-515$.

[8] Picaut, J.: Numerical modeling of urban sound fields by a diffusion process. Appl. Acoust. 63 (2002) 965-991.

[9] Kang, J.: Numerical modelling of the sound field in urban streets with diffusely reflecting boundaries. J. Sound Vib. 258 (2002) 793-813.

[10] Iu, K.K., Li, K.M.: The propagation of sound in narrow street canyons. J. Acoust. Soc. Am. 112 (2002) 537-550.

[11] Heutschi, K.: A simple method to evaluate the increase of traffic noise emission level due to buildings for a long straight street. Appl. Acoust. 44 (1995) 259-274.

[12] Horoshenkov, K., Chandler-Wilde, S., Hothersall, D.: An efficient method for the prediction of sound propagation in a canyon. Proc. of ICA, Rome, Italy (2001).

[13] Oldham, D.J., Radwan, M.M.: Sound propagation in city streets. Build. Acoust. 1 (1994) 65-87.

[14] Wu, S., Kittinger, E.: On the relevance of sound scattering to the prediction of traffic noise in urban areas. Acustica 81 (1995) 36-42.

[15] Steenackers, P., Myncke, H., Cops, A.: Reverberation in town streets. Acustica 40 (1978) 115-119.

[16] Picaut, J., Simon, L.: A scale model experiment for the study of sound propagation in urban areas. Appl. Acoust. 62 (2001) 327-340.

[17] Horoshenkov, K.V., Hothersall, D.C., Mercy, S.E.: Scale modelling of sound propagation in a street canyon. J. Sound Vib. 223 (1999) 795-819.

[18] Lyon, R.H., Holmes, D.G., Donovan, P.R., Kursmark, R.: Sound propagation in city streets. Final report, Department of transportation contract DOT/TSC93, MIT (1974).

[19] Schlatter, W.R.: Sound power measurements in a semi-confined space. M.Sc. Thesis, Department of Mechanical Engineering, MIT (1971).

[20] Kang, J.: Numerical modeling of the sound fields in urban squares. J. Acoust. Soc. Am. 117 (2005) 3695-3706. 
[21] Kihlman, T.: National Action Plan against Noise. Allmänna Förslaget, Stockholm, Sweden. Summary of "Handlingsplan mot buller" (in Swedish) (1993).

[22] Skånberg, A., Öhrström, E.: Adverse health effects in relation to urban residential soundscapes. J. Sound Vib. 250 (2002) 151-155.

[23] Kihlman, T., Öhrström, E., Skånberg, A.: Adverse health effects of noise and the value of access to quietness in residential areas. Proceedings of Internoise, Dearborn, USA (2002) paper 484.

[24] Van Renterghem, T., Botteldooren, D.: Numerical simulation of sound propagation over rows of houses in the presence of wind. Proceedings of the $10^{\text {th }}$ int. conf. on sound and vibration, Stockholm, Sweden (2003) 1381-1388.

[25] Ögren, M., Kropp, W.: Road traffic noise propagation between two dimensional city canyons using an equivalent sources approach. Acta Acustica united with Acustica 90 (2004) 293-300.

[26] Hornikx M.: Towards a parabolic equation for modeling urban sound propagation. $11^{\text {th }}$ Long Range Sound Propagation Symposia, Fairly, Vermont (2004).

[27] Hornikx M., Forssén: The 2.5-dimensional equivalent sources method for directly exposed and shielded urban canyons. Accepted for publication in J. Acoust. Soc. Am.

[28] Picaut, J., Le Polles , T., L'Hermite, T., Gary, V.: Experimental study of sound propagation in a street. App. Acoust. 66 (2005) 149-173.

[29] Theurer, W.: Typical building arrangements for urban air pollution modelling. Atmos. Env. 33 (1999) 4057-4066.

[30] MLSSA 10.0, acoustical measurement system, DRA laboratories, Sarasota, Florida, USA.

[31] Brüel \& Kjaer, type 4138, 1/8 inch condenser microphone, product data sheet. Nærum, Denmark.

[32] Accuton $C^{2} 12-6$, ceramic driver tweeter, Thiel \& Partner GmbH, Pulheim, Germany.

[33] Matlab 6.5, The Mathworks, Natick, Massachusetts, USA. 
[34] Pierce, A.D.: Acoustics, an introduction to its physical principles and applications. The Acoustical Society of America, Melville, NY, USA (1981).

[35] Almgren, M.: Acoustic boundary layer influence on scale model simulation of sound propagation: experimental verification. J. Sound Vib. 110 (1986) 247-259.

[36] Salomons, E.M.: Computational atmospheric acoustics. Kluwer Academic Publishers (2001).

[37] Akil, H.A., Oldham, D.J.: Digital correction for excessive air. Absorption in acoustic scale models. Proc. of the Institute of Acoustics, Salford, UK 16 (1994) 525-536.

[38] Akil, H.A., Oldham, D.J.: Digital compensation for excess air absorption in acoustic scale models. Proc. Euro Noise, Lyon, France 1 (1995) 73-78.

[39] Polack, J.D., Marshall, A.H., Dodd, G.: Digital evaluation of the acoustics of small models: the MIDAS package. J. Acoust. Soc. Am. 85 (2001) 185-193.

[40] Bracewell, R.N.: The Fourier transform and its applications. McGraw-Hill (2000).

[41] Jonasson, H., Storeheier, S., Nord 2000: New Nordic Prediction Method for Road Traffic Noise. SP Rapport 2001:10, Borås, Sweden (2001).

[42] Lee, S.K.: An acoustic decay measurement based on time-frequency analysis using wavelet transform. J. Sound Vib. 252 (2002) 141-153.

[43] Pierce, A.D.: Diffraction of sound around corners and over wide barriers. J. Acoust. Soc. Am. 55 (1974) 941-955.

[44] Svensson, U. P.:"EDBtoolbox", Matlab implementation of the algorithms in [45].

[45] Svensson, P.U., Fred, R.I., Vanderkooy, J.: An analytic secondary source model of edge diffraction impulse responses. J. Acoust. Soc. Am. 106 (1999) 2331-2344.

[46] Kang, J.: Sound propagation in street canyons: Comparison between diffusely and geometrically reflecting boundaries. J. Acoust. Soc. Am. 107 (2000) 1394-1404.

[47] Schroeder, M.R.: New method of measuring reverberation time. J. Acoust. Soc. Am. 37 (1965) 409-412. 
[48] Van Renterghem, T., Salomons, E., Botteldooren, D.: Parameter study of sound propagation between city canyons with a coupled FDTD-PE model. App. Acoust. 67 (2006) 487-510.

[49] Chien, C. F., Soroka, W. W.: Sound propagation along an impedance plane. J. Sound Vib. 43 (1975) 9-20.

[50] Allard, J.F.: Propagation of sound in porous media: modeling sound absorbing materials. Chapman \& Hall, London (1993).

[51] Attenborough, K.: Models for the acoustical properties of the air saturated granular media. Acta Acustica 1 (1993) 213-226.

[52] Lagarias, J.C., Reeds, J.A., Wright, M. H., Wright, P. E.: Convergence Properties of the Nelder-Mead Simplex Method in Low Dimensions. SIAM J. Optimization 9 (1998) 112-147.

[53] Bultheel, A.: Wavelets with applications in signal and image processing. Course material University of Leuven, Belgium (2003).

[54] Torrence, C., Compo, G.P.: A practical guide to wavelet analysis. Bulletin of the American Meteorological Society (1998) 61-78.

[55] Farge, M.: Wavelet transforms and their applications to turbulence. Ann. Rev. Fluid Mech. 24 (1992) 395-457. 


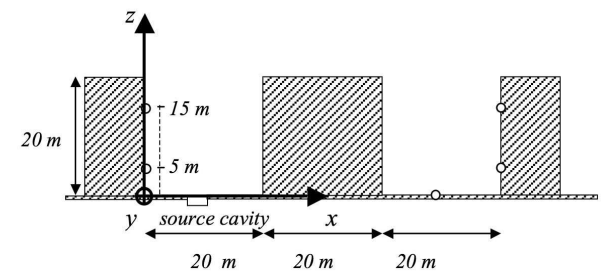

a)

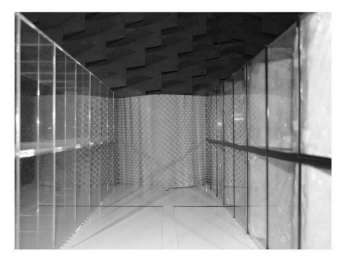

c)

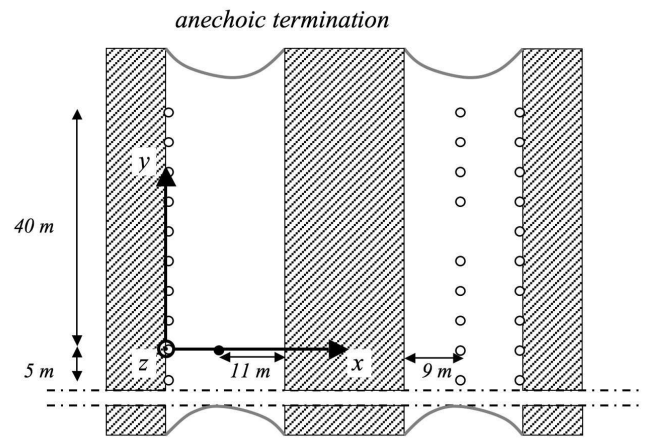

g)

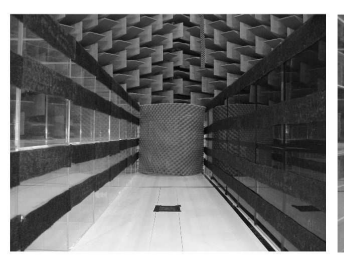

d)

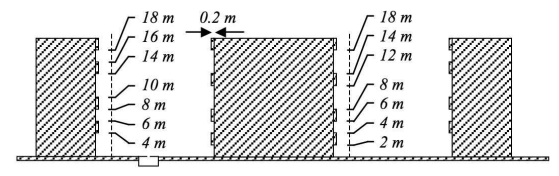

b)
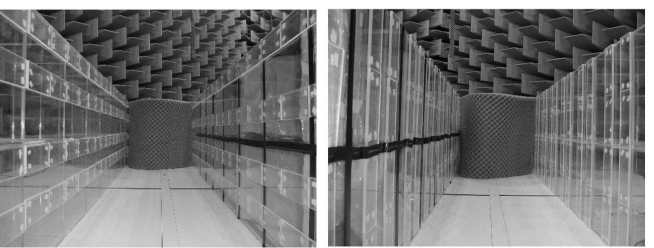

e)

f)

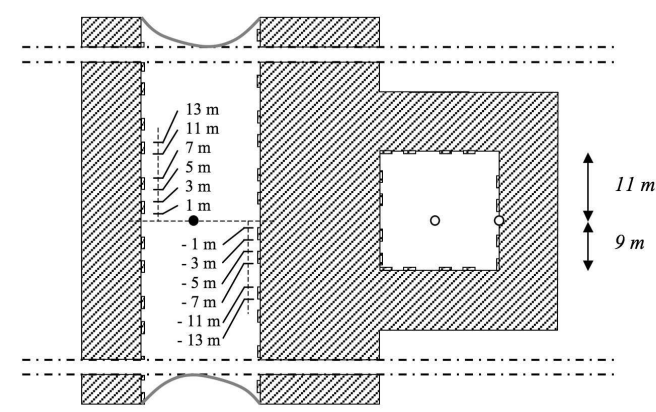

h)

receive

Figure 1: Scale model set-up. a) Cross section with rigid façades, b) Cross section with horizontally oriented façade patches (absorption or diffusion), c) View in the shielded canyon with rigid façades, d) View in the directly exposed canyon with horizontally oriented façade absorption patches, e) View in the shielded canyon with horizontally oriented façade diffusion patches, $f$ ) View in the shielded canyon with vertically oriented façade diffusion patches, g) Top view of the parallel canyons, h) Top view in the case of a closed courtyard at the shielded side and with vertically oriented façade diffusion patches. The full scale dimensions are shown. 


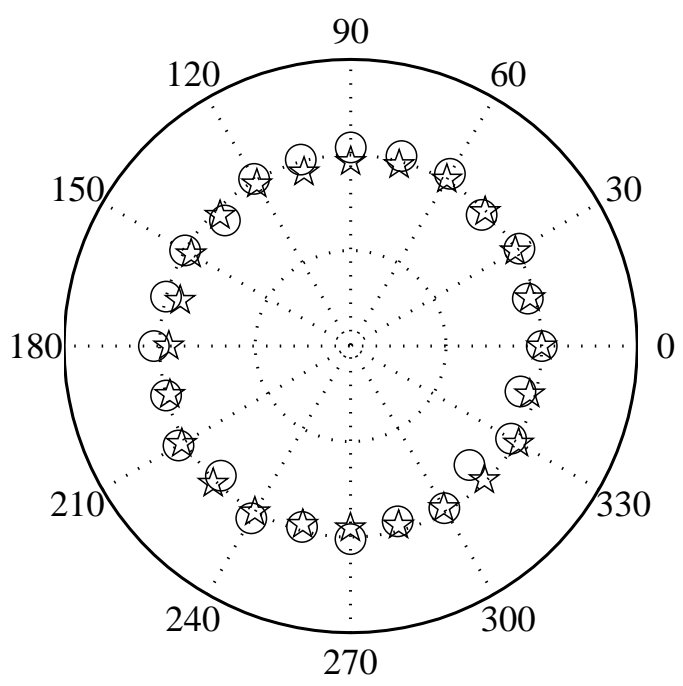

horizontal directionality (deg)

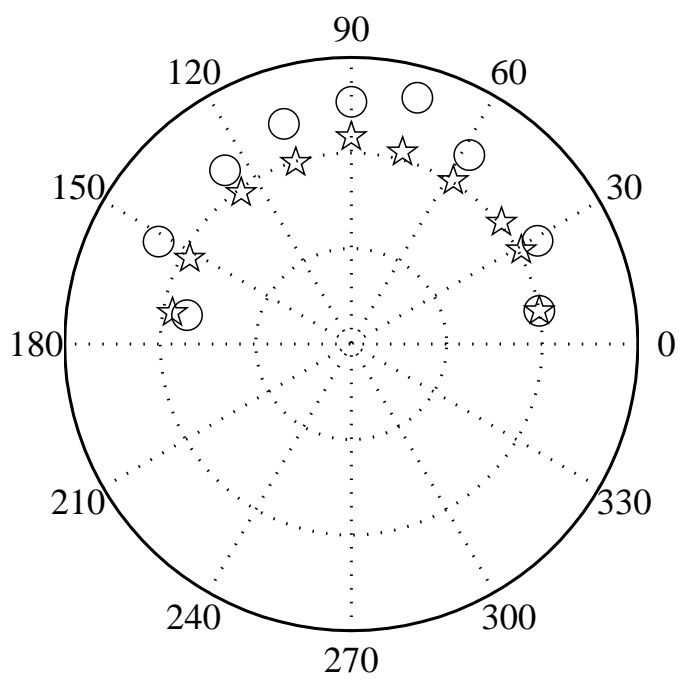

vertical directionality (deg)

Figure 2: Horizontal and vertical directionality of the used sound source. Stars: $10 \mathrm{~mm}$ source hole at the $10 \mathrm{kHz}$ 1/3-octave band, Circles: $3 \mathrm{~mm}$ source hole at the $40 \mathrm{kHz}$ 1/3-octave band. The level increment between gridlines is $5 \mathrm{~dB}$. 


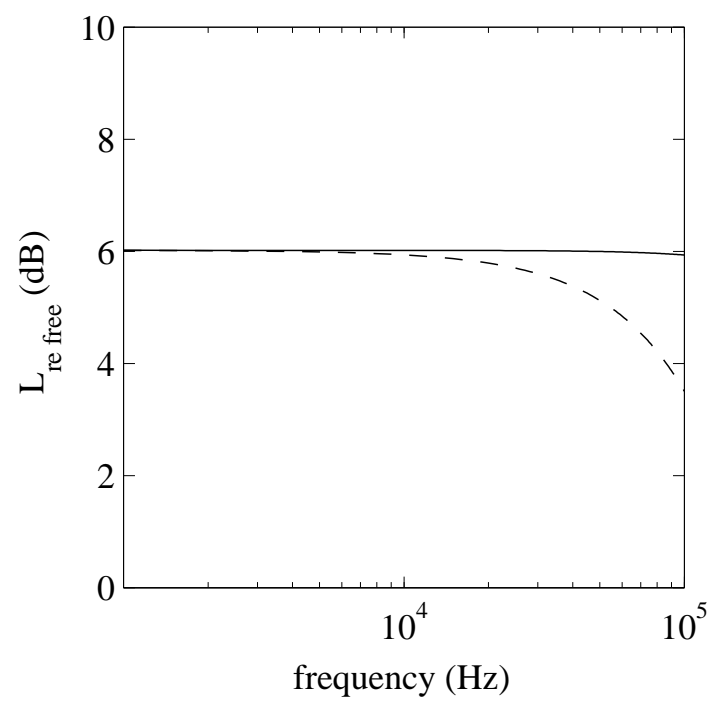

a)

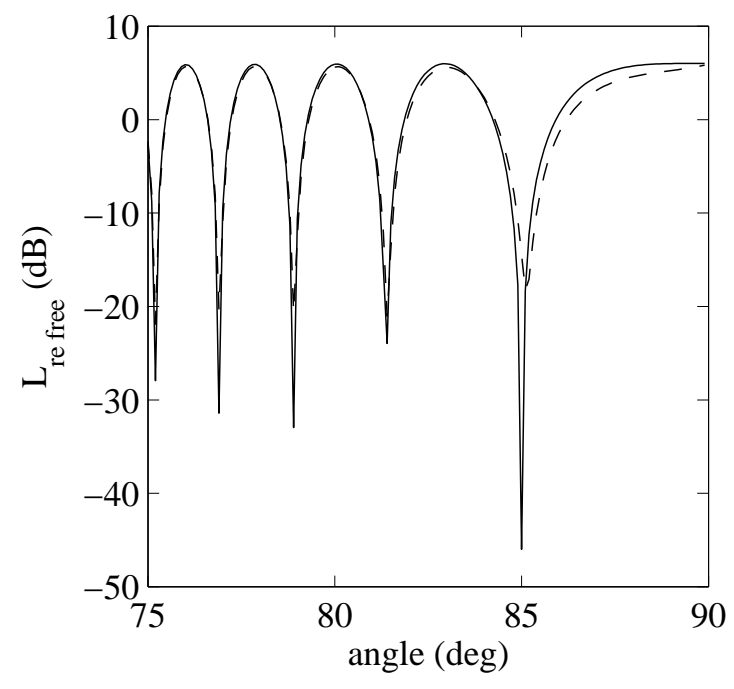

b)

Figure 3: The level relative to the free field level of sound propagation over a rigid boundary. The horizontal source-receiver distance is $1 \mathrm{~m}$, the vertical distance varies with angle of incidence. a) The frequency dependent $L_{\text {refree }}$ with an angle of sound wave incidence relative to the normal with the surface of $89^{\circ}, b$ ) The angular dependent $L_{\text {refree }}$ with $f=45 \mathrm{kHz}$. Solid: A zero admittance boundary, Dashed: A boundary with an admittance due to the boundary layer effect. 


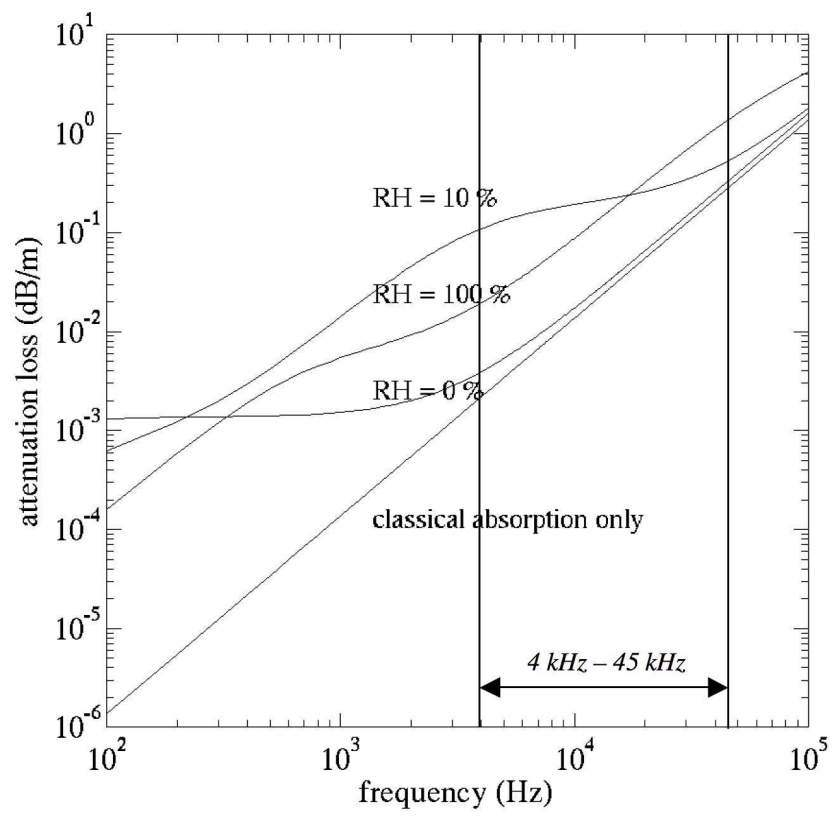

Figure 4: Attenuation loss for sound propagation through air at $293 \mathrm{~K}$ and $1.103 \mathrm{hPa}$ according to ISO 9613-1:1993. The frequency range of the scale model measurements is highlighted. 


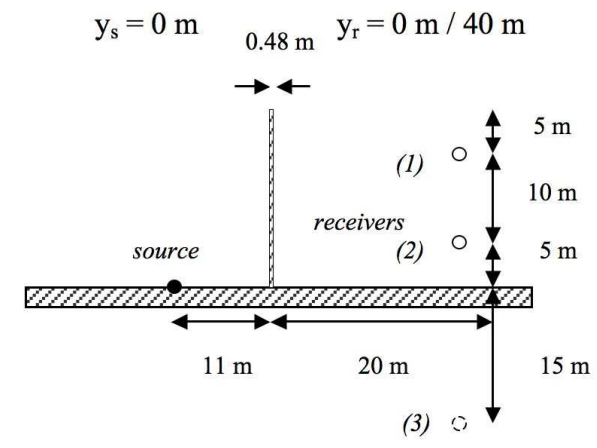

$\mathrm{y}_{\mathrm{s}}=0 \mathrm{~m} \quad \mathrm{y}_{\mathrm{r}}=0 \mathrm{~m} / 40 \mathrm{~m}$
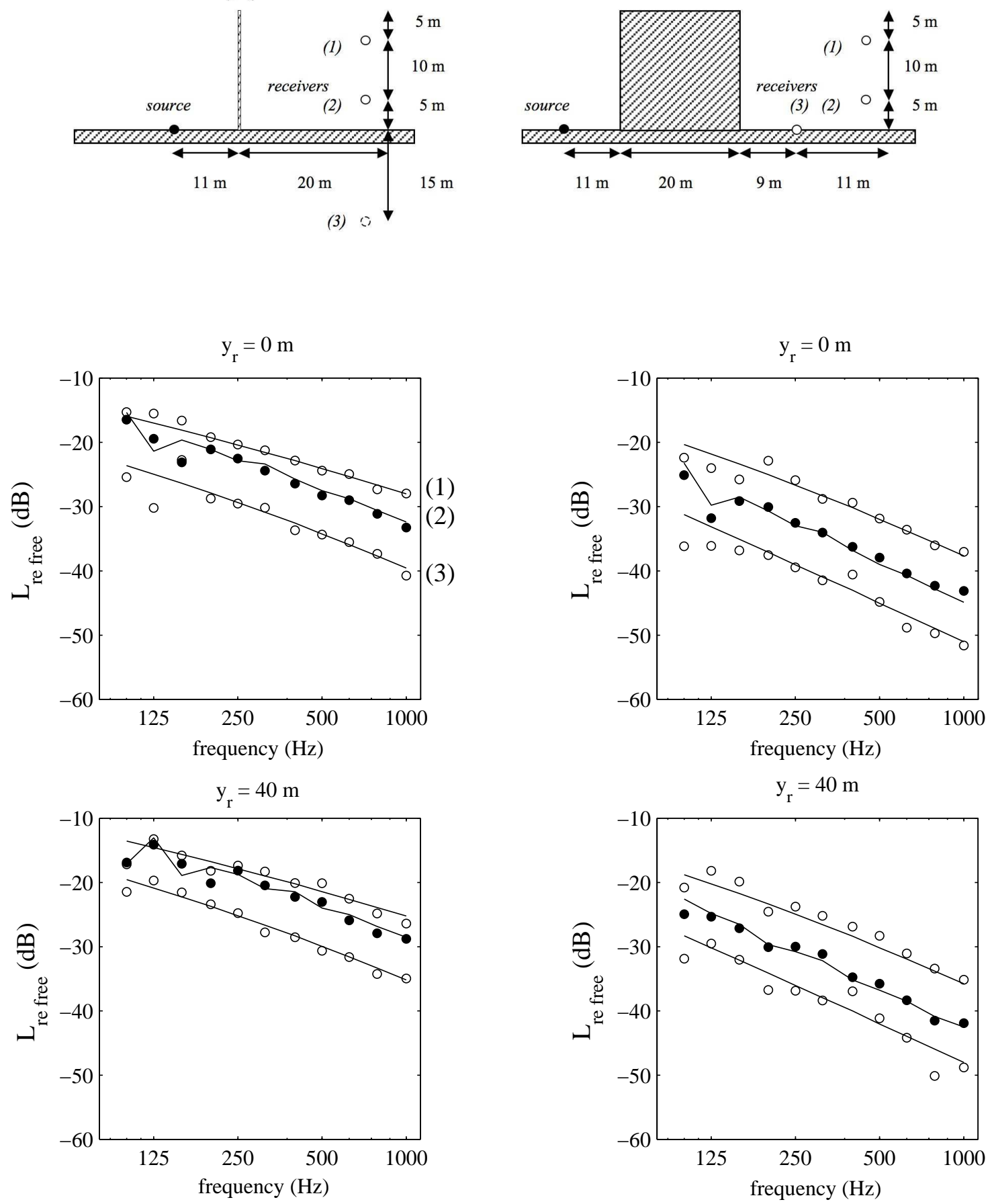

Figure 5: $L_{\text {refree }}$ for a thin (left) and thick (right) barrier in 1/3-octave bands. Circles: Measurements, Solid lines: Pierce diffraction theory. For positions 2 (and position 3 in the thick barrier case), the direct diffracted and ground reflected waves have been summed. 

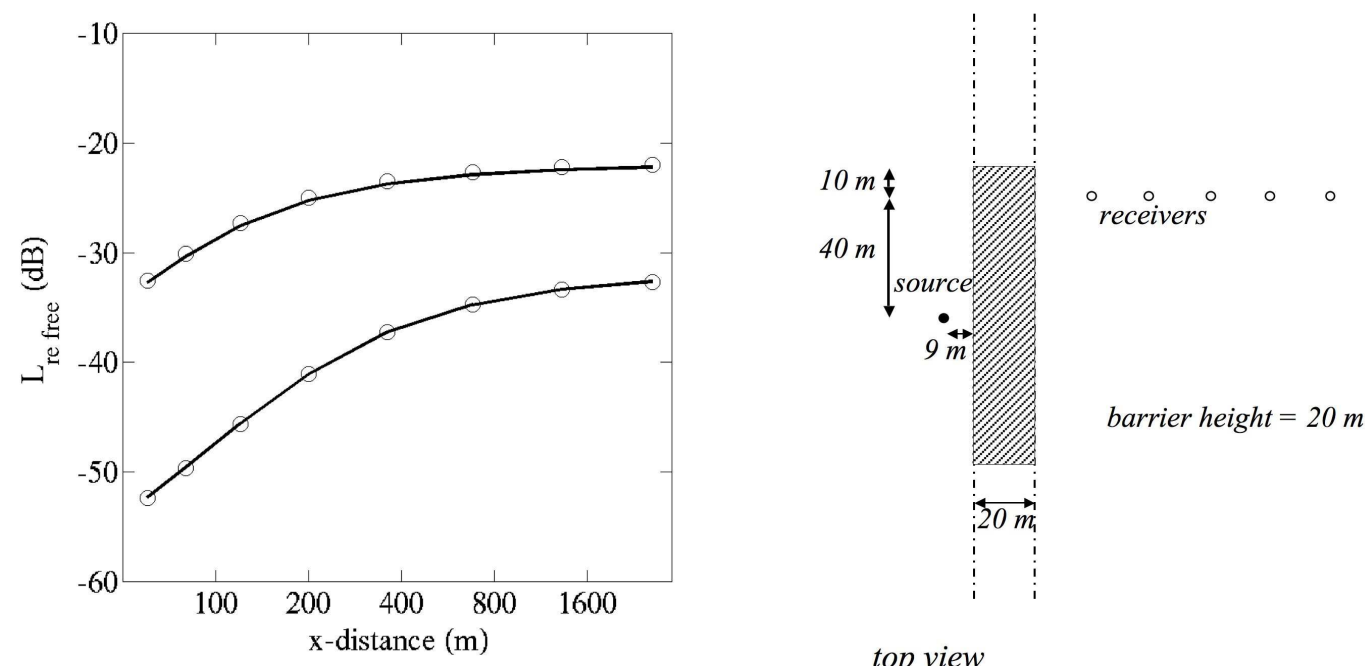

top view

Figure 6: $L_{\text {refree }}$ calculated as a function of the distance from a $20 \mathrm{~m}$ wide and high barrier in 1/3-octave bands. Source located at (9,0,0), receivers at (x,40,0). Thick: Infinitely long screen calculation [43], Circles: $100 \mathrm{~m}$ long screen calculation [44]. Diffraction around the barrier ends is neglected. Upper results are for $100 \mathrm{~Hz}$, lower results are for $1000 \mathrm{~Hz}$. 
a)

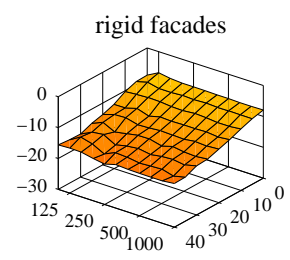

b)

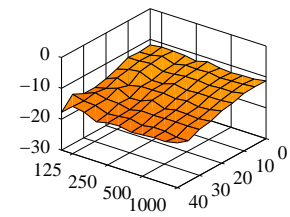

c)

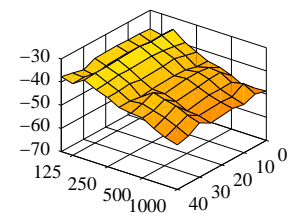

d)

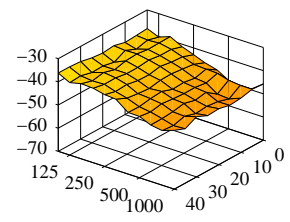

e)

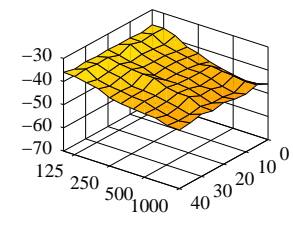

absorption
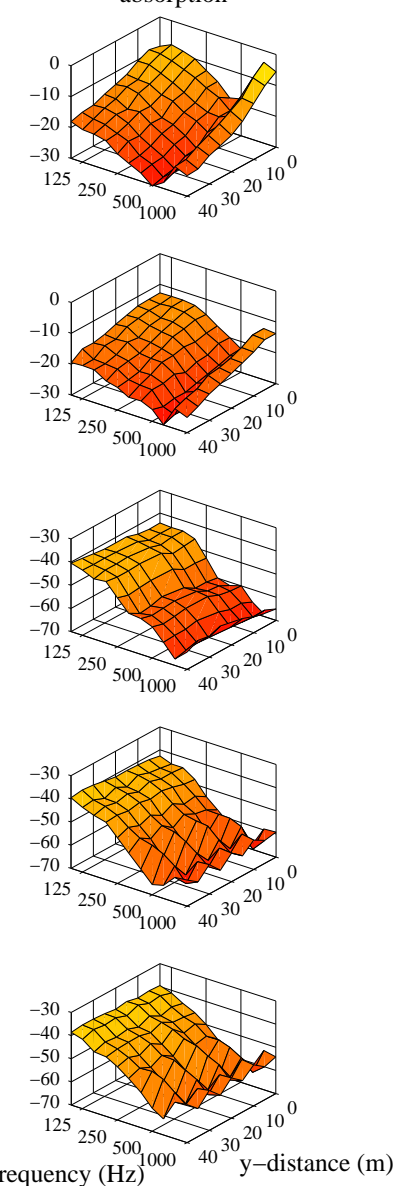
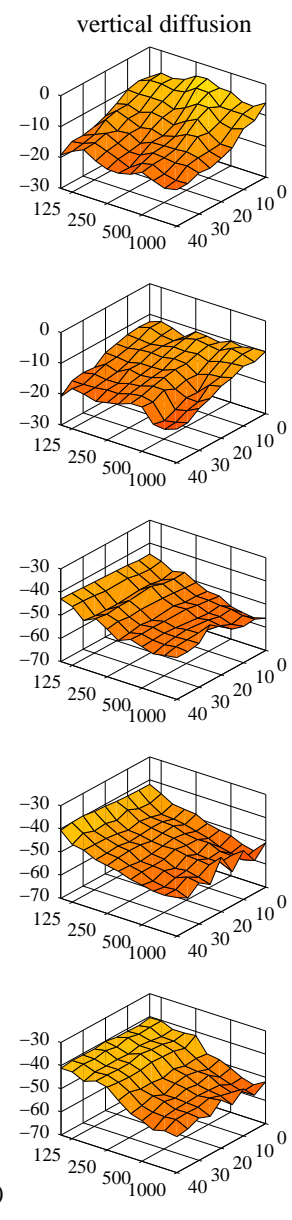
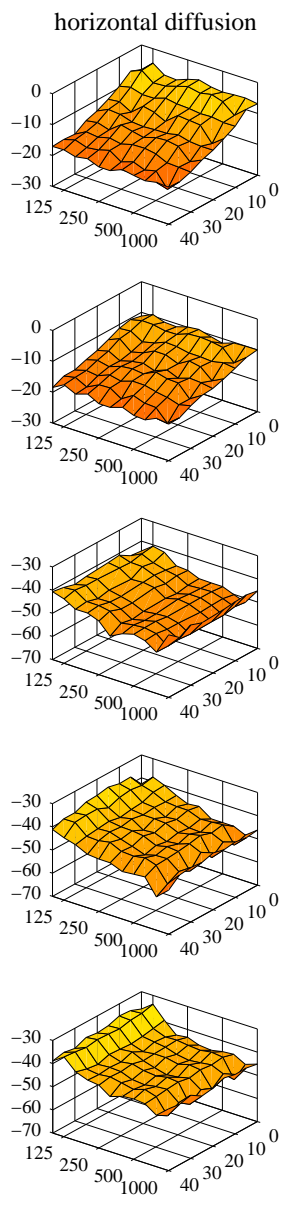

Figure 7: Measured $L_{r e f r e e, 1 m}$ results for: a) Directly exposed street canyon, $z=5 \mathrm{~m}$, b) Directly exposed street canyon, $z=15 \mathrm{~m}, \mathrm{c}$ ) Shielded canyon, $z=0 \mathrm{~m}, \mathrm{~d}$ ) Shielded canyon, $z=5 \mathrm{~m}, e$ ) Shielded canyon, $z=15 \mathrm{~m}$. 

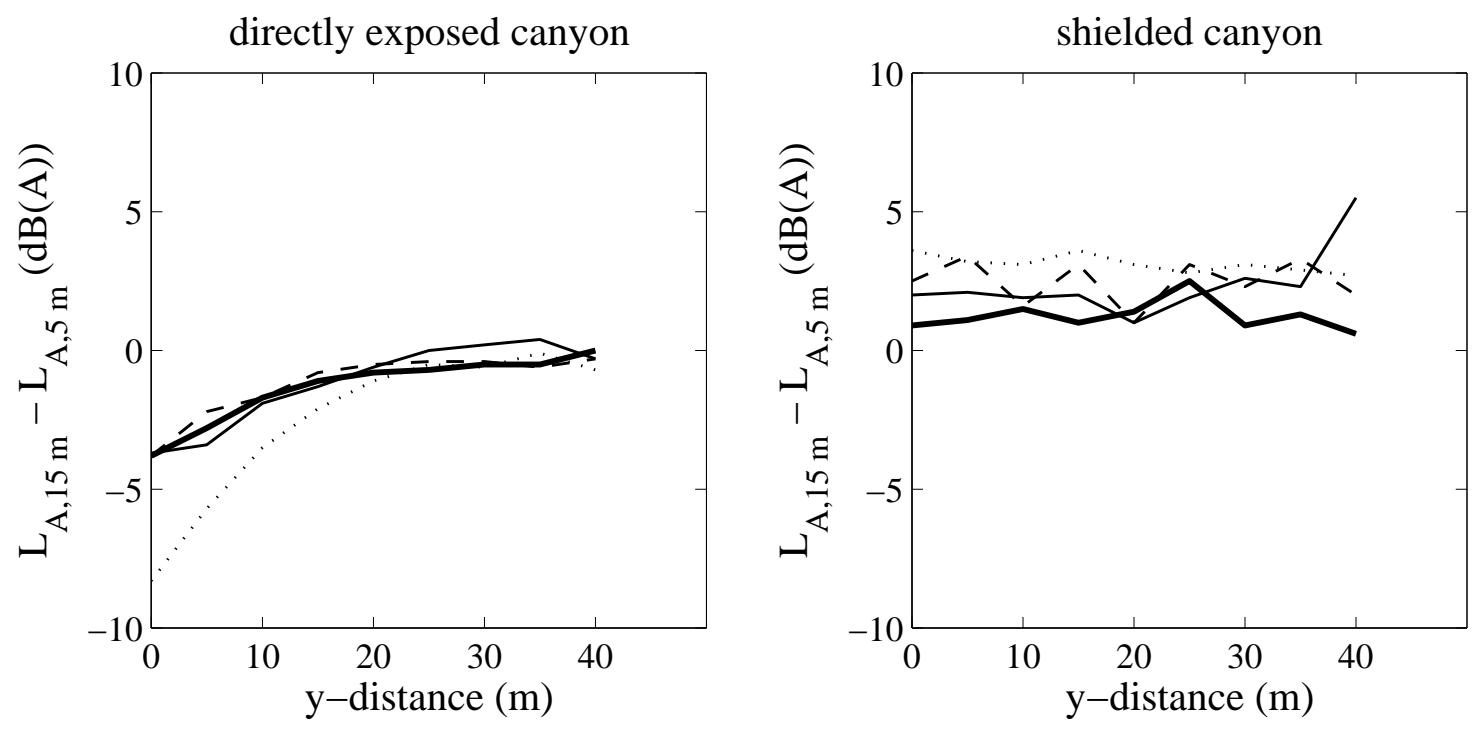

Figure 8: Level differences between receiver positions at $z=15 \mathrm{~m}$ and $z=5 \mathrm{~m}$ in the directly exposed street canyon (left) and shielded canyon (right). Solid thick: Rigid façades, Dashed: Horizontally oriented façade diffusion patches, Solid thin: Vertically oriented façade diffusion patches, Dotted: Horizontally oriented façade absorption patches. 
a)

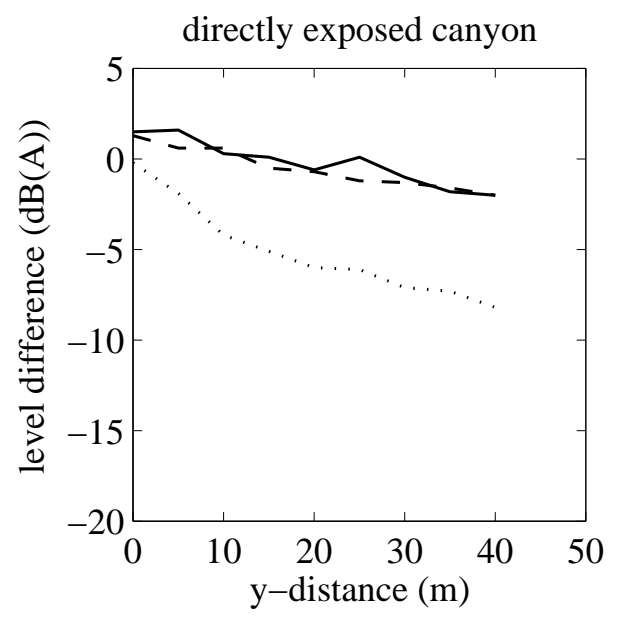

b)

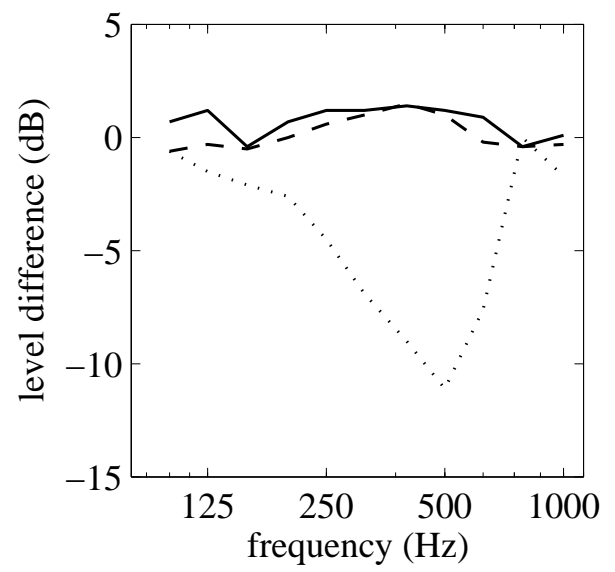

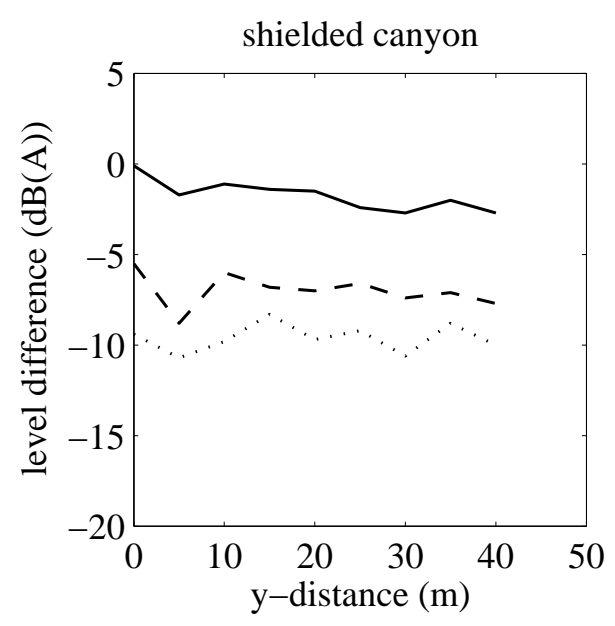

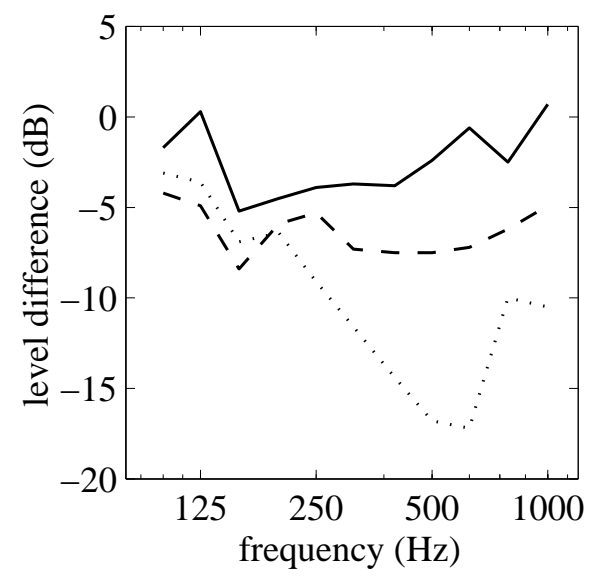

Figure 9: Levels relative to the levels with rigid façades. a) Levels averaged over all receiver height positions, b) Levels averaged over all positions. Dashed: Horizontally oriented façade diffusion patches, Solid thin: Vertically oriented façade diffusion patches, Dotted: Horizontally oriented façade absorption patches. 


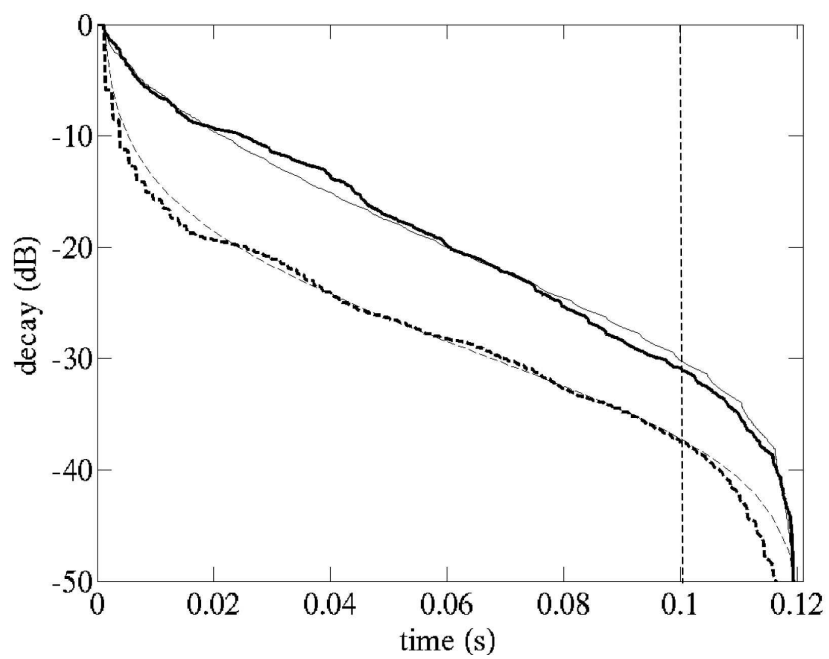

Figure 10: Schroeder's curves for receiver position (0,0,15), $250 \mathrm{~Hz}$ 1/3-octave band. The time is at the 1 to 40 scale. Solid thick: Closed courtyard situation measured, Solid thin: Closed courtyard situation fitted ISM, Dashed thick: Street canyon situation measured, Dashed thin: Street canyon situation fitted ISM. The fitting procedure was done up to $0.1 \mathrm{~ms}$. 
a)

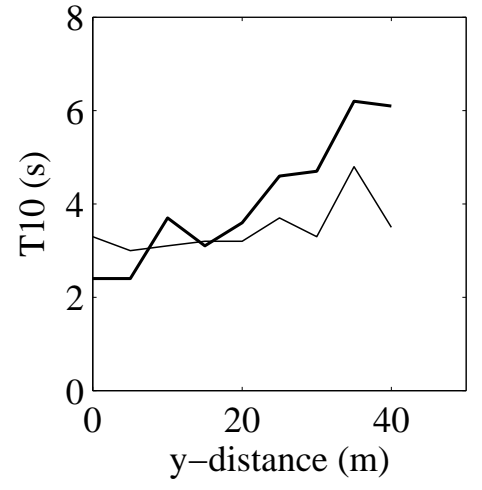

b)

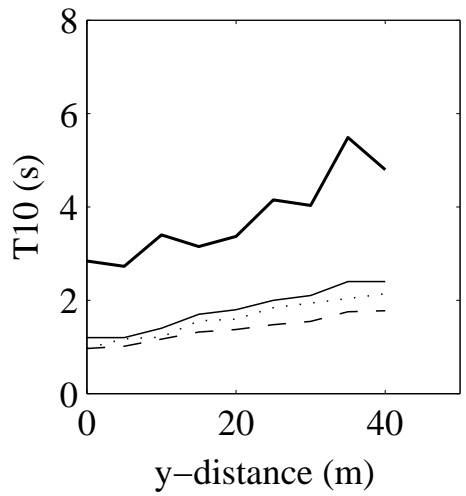

c)

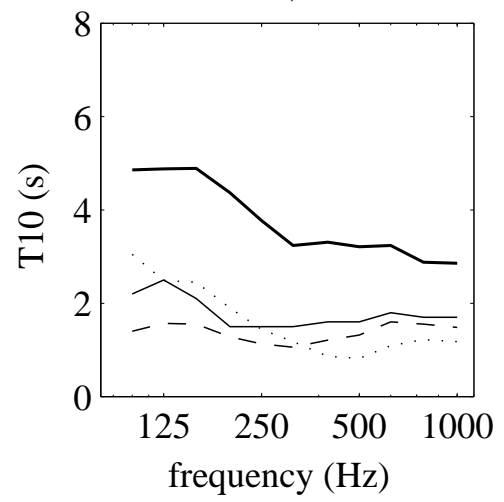

Figure 11: T10s in the exposed street canyon. a) T10s averaged over 1/3-octave bands for two receiver heights in the rigid façades case. Solid thick: $z=5 \mathrm{~m}$, Solid thin: $z=$ $15 \mathrm{~m}$, b) T10s averaged over 1/3-octave bands and receiver height positions, c) T10s averaged over all receiver positions. Solid thick: Rigid façades, Dashed: Horizontally oriented façade diffusion patches, Solid thin: Vertically oriented façade diffusion patches, Dotted: Horizontally oriented façade absorption patches. 


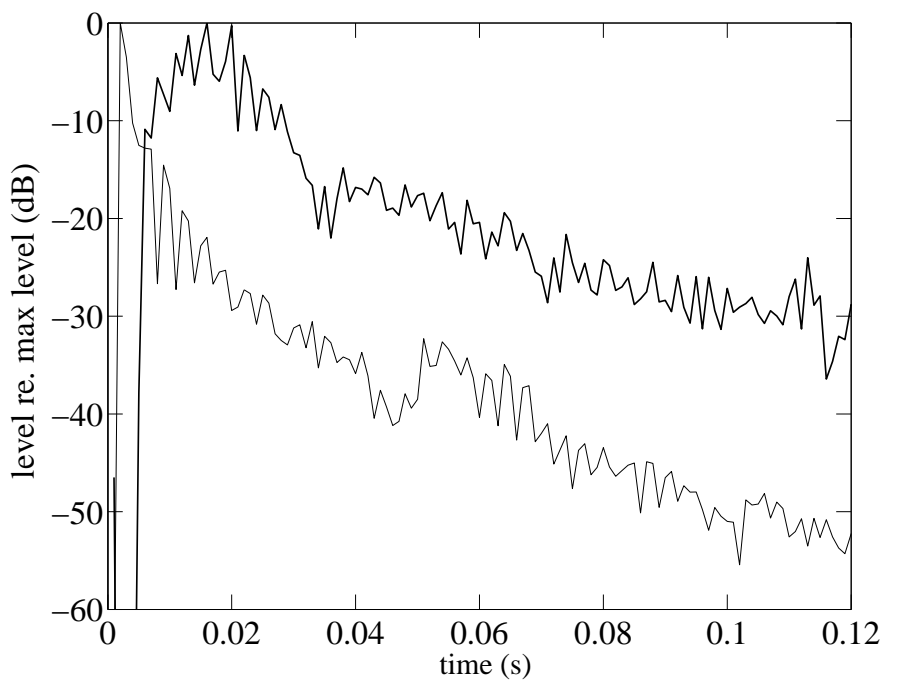

Figure 12: Energy-time curves for receiver positions in the directly exposed and shielded canyon, $250 \mathrm{~Hz}$ 1/3-octave band. Thick: Receiver position (60,0,5), Thin: Receiver position $(0,0,5)$. The time is shown at the 1 to 40 scale and an integration time of 0.001 s has been used. 
a)
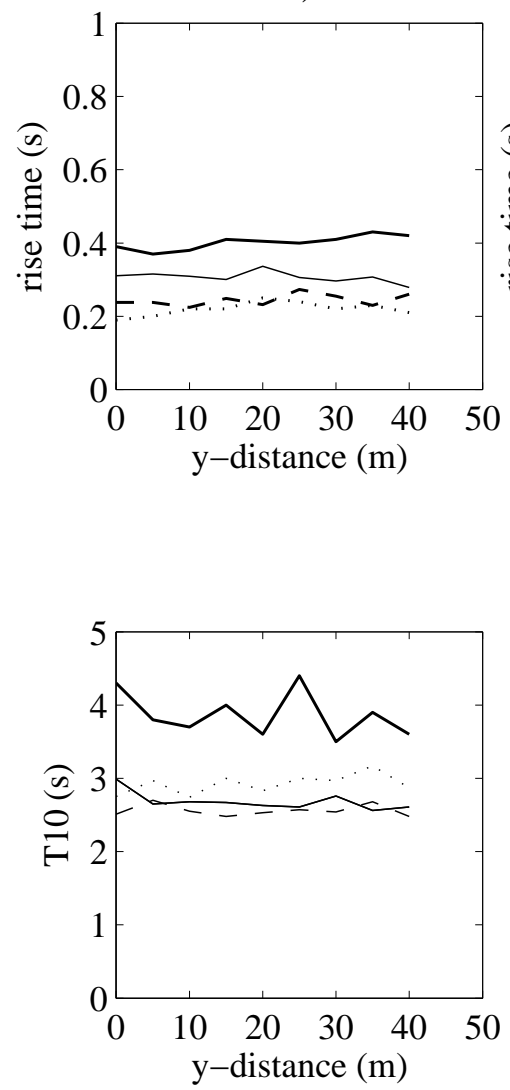

b)

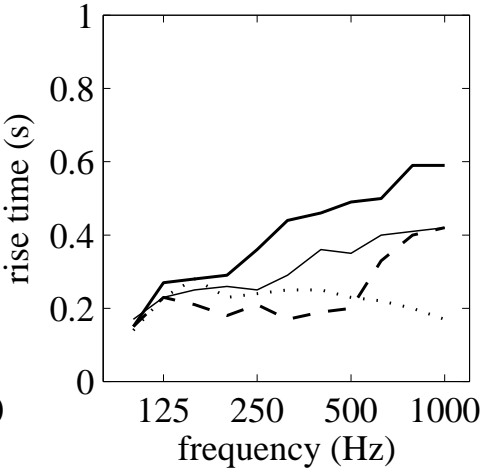

c)
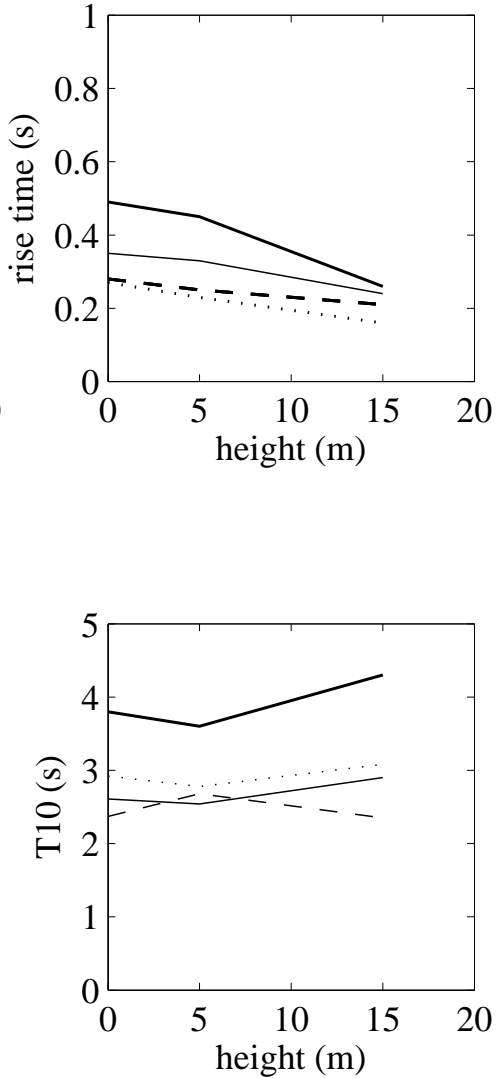

Figure 13: Rise time and T10 results in the shielded canyon. a) Results averaged over 1/3-octave bands and receiver height positions, $b$ ) Results averaged over all receiver positions, c) Results averaged over 1/3-octave bands and for $y=0 \mathrm{~m}$. Line indices as in Figure 11c. 

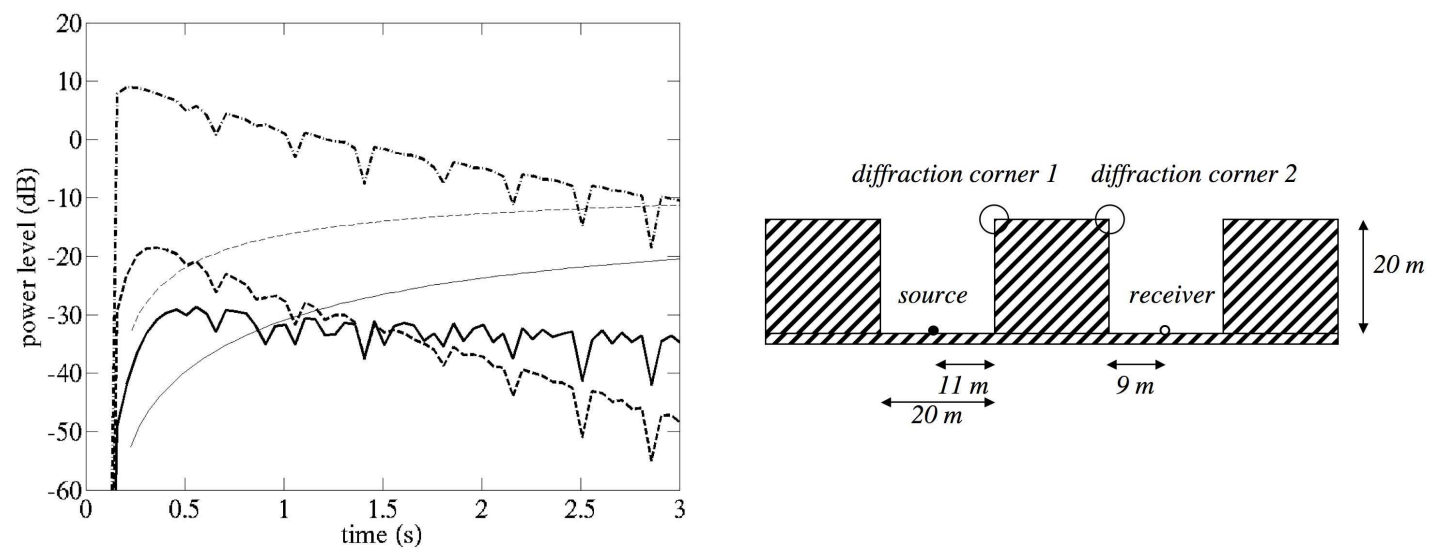

Figure 14: Calculated energy-time curves in the shielded canyon for the sketched cross section. Dash-dotted: Energy-time curve with diffraction factor equal to 1, Dashed thin: Diffraction coefficient for $100 \mathrm{~Hz}$, Solid thin: Diffraction coefficient for $1000 \mathrm{~Hz}$, Dashed thick: Energy-time curve with the diffraction coefficient for $100 \mathrm{~Hz}$, Solid thick: energy-time curve with diffraction coefficient for $1000 \mathrm{~Hz}$. 

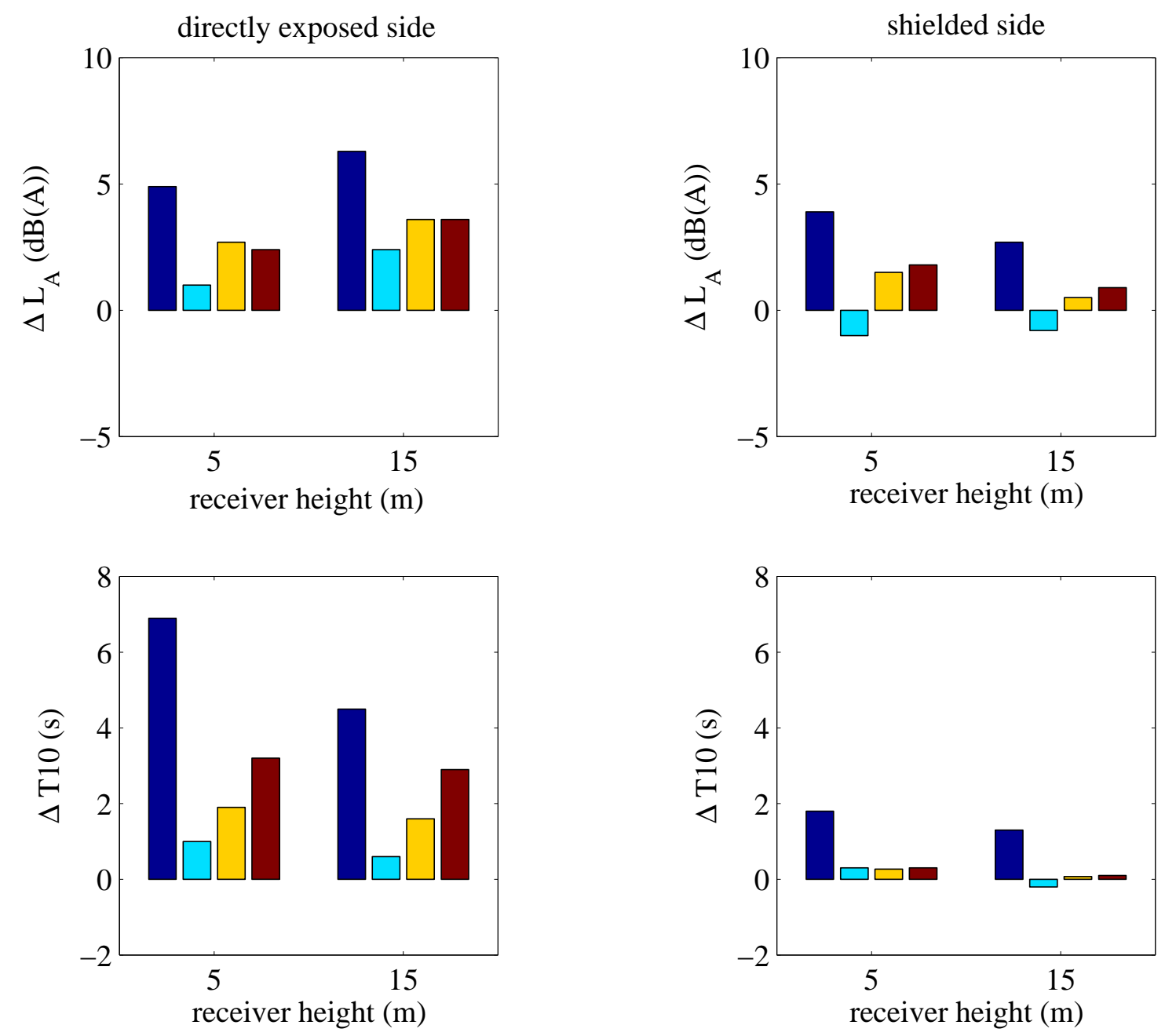

Figure 15: Differences in level and T10 between closed courtyard and canyons. Levels are for receivers positions with $y=0 \mathrm{~m}$. The T10 results are 1/3-octave band averaged. First bar: Rigid façades, Second bar: Absorption patches applied, Third bar: Horizontal oriented diffusion patches applied, Fourth bar: Vertical oriented diffusion patches applied. 


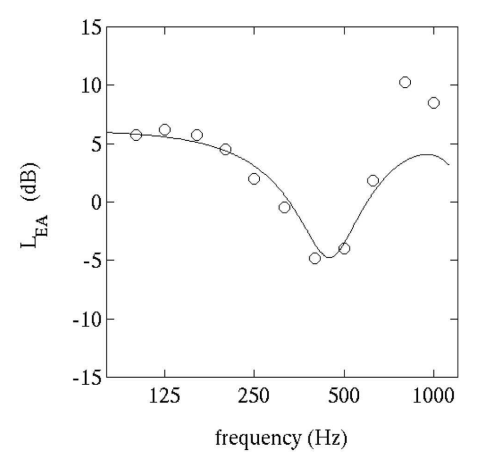

a)

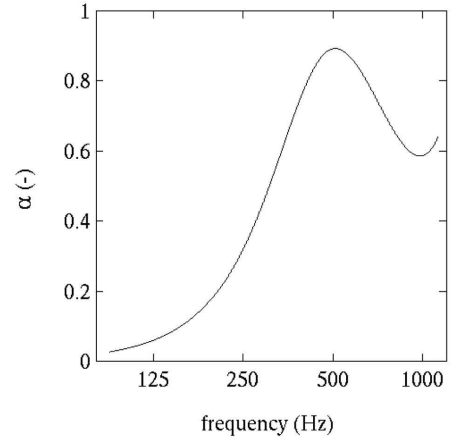

b)

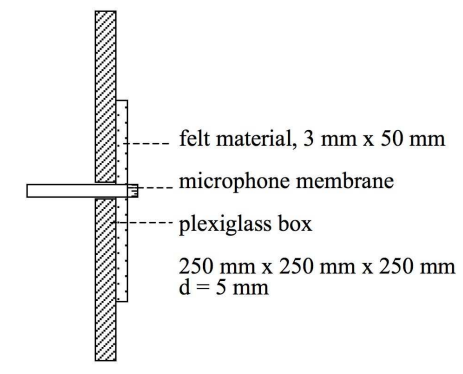

c)

Figure 16: Excess attenuation of $3 \mathrm{~mm}$ velvety felt. Source position $(x, y, z)=(9,0,0)$, receiver position $(0,0,15)$ and felt at $(0,0,4-6)$. Coordinates according to Figure 1. a) Fitted excess attenuation curve. Solid line: Fitted results, Circles: Measured, b) Obtained absorption coefficients for normal wave incidence, c) Close up of the microphone position during the impedance measurement. 
a)

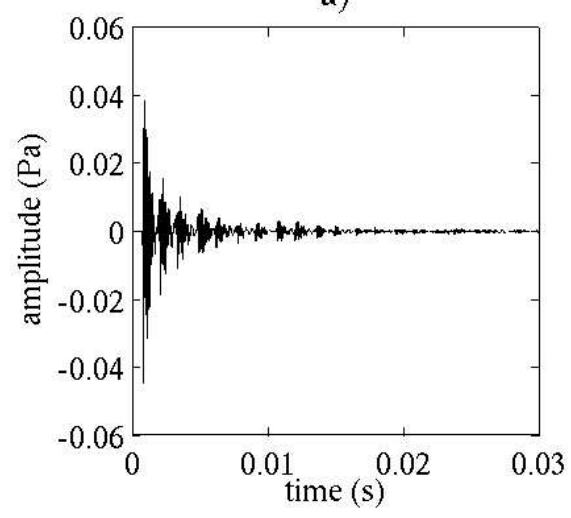

c)

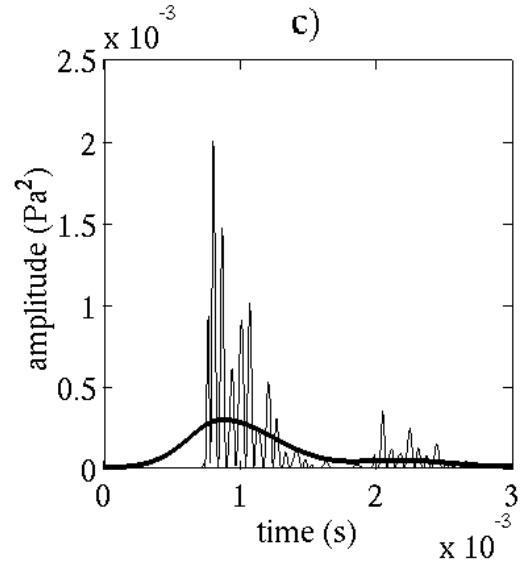

b)

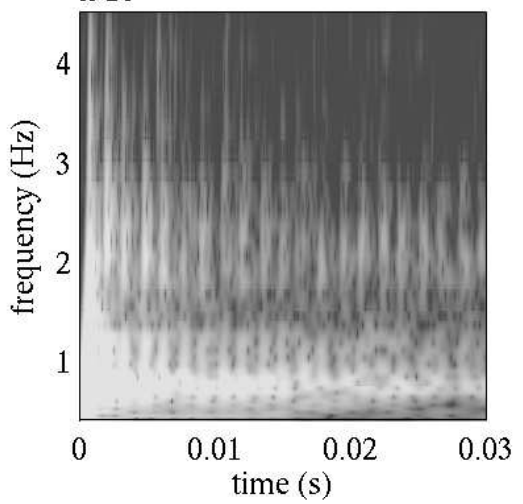

d)

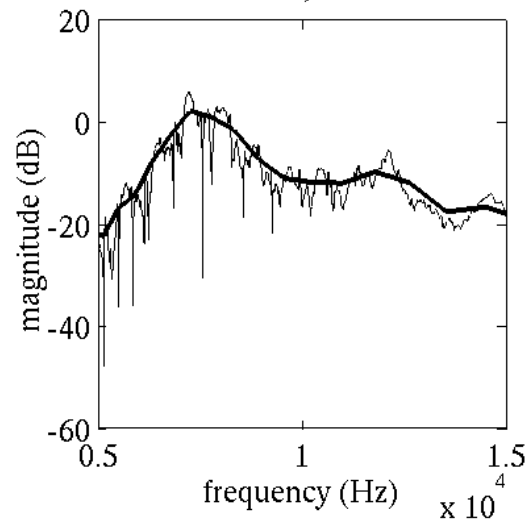

Figure 17: Example of a signal transformed by the wavelet transform, its energy-time representation and its power spectrum representation. The time is at the 1 to 40 scale. 
a)

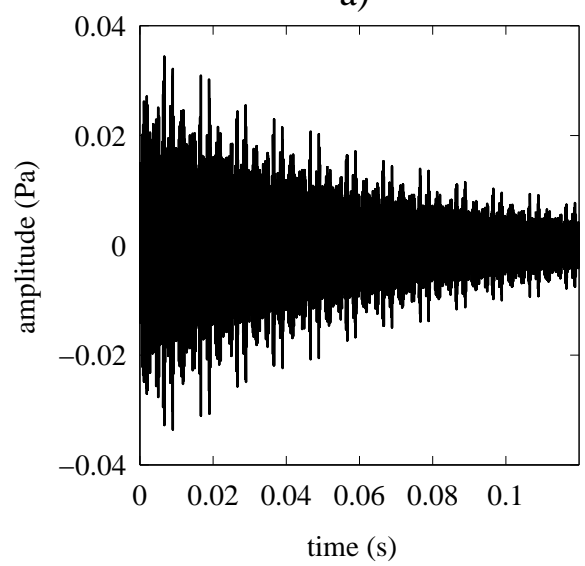

c)

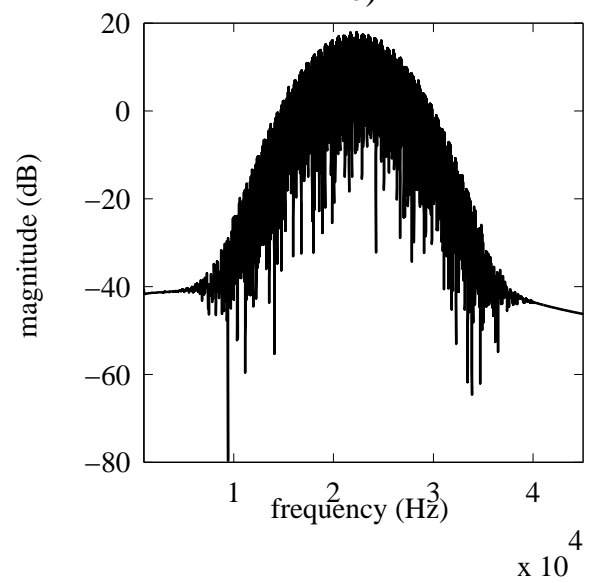

e)

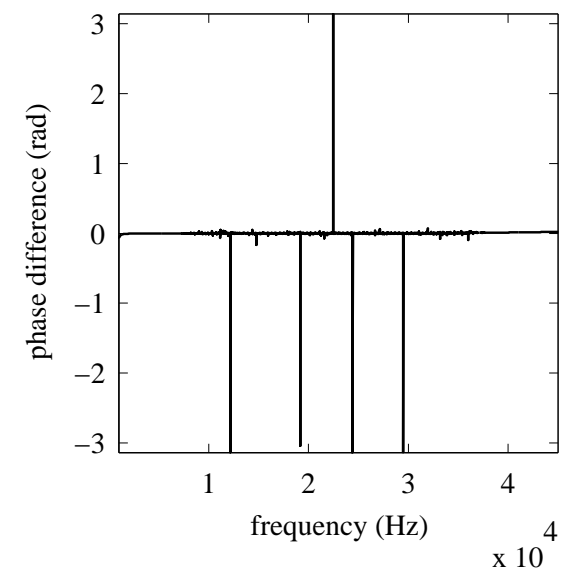

b)

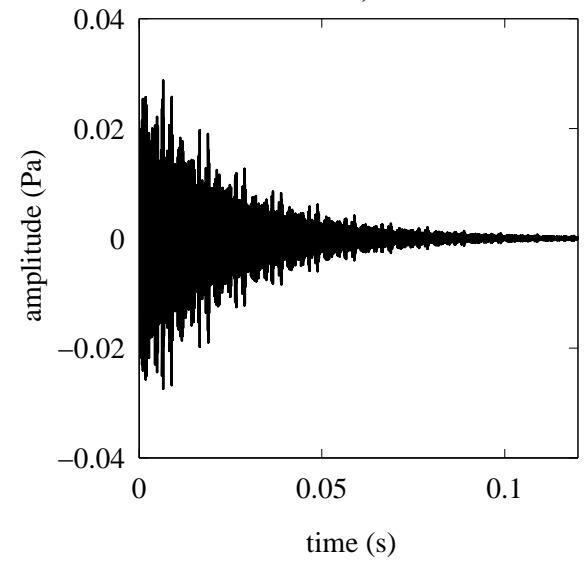

d)

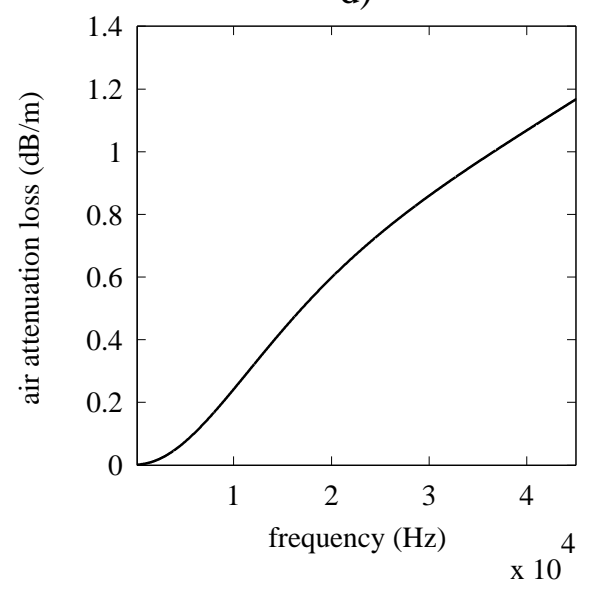

f)

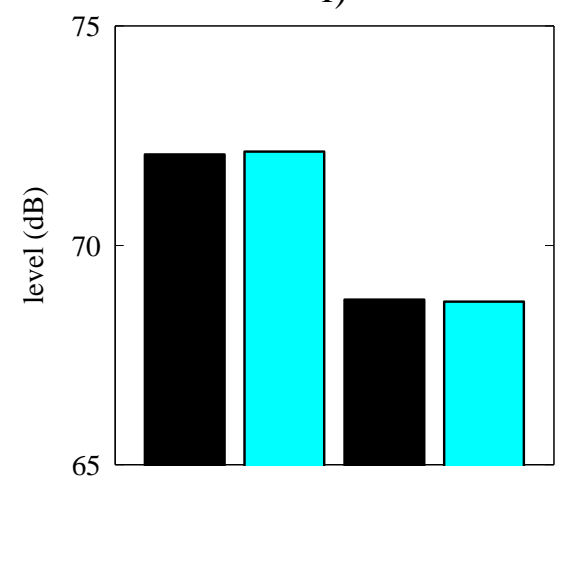

Figure 18: Synthesized signal with a frequency content corresponding to a scale model measurement. a) Synthesized signal, b) Damped signal, c) Frequency content of undamped signal, d) Air attenuation applied to the signal, e) Phase difference between signal and damped signal, corrected by the wavelet method, f) Levels of the the signal in a) (left pair), levels of the signal in b) (right pair). First and third bar represent the levels of the original signals, the second and fourth bar correspond to the level of the reconstructed signal using the wavelet method. 